\title{
Loss of cholinergic innervation differentially affects eNOS-mediated blood flow, drainage of $A \beta$ and cerebral amyloid angiopathy in the cortex and hippocampus of adult mice
}

\author{
Shereen Nizari ${ }^{1}$, Jack A. Wells ${ }^{2}$, Roxana O. Carare ${ }^{3}$, Ignacio A. Romero ${ }^{1}$ and Cheryl A. Hawkes ${ }^{1,4^{*}}$ (D)
}

\begin{abstract}
Vascular dysregulation and cholinergic basal forebrain degeneration are both early pathological events in the development of Alzheimer's disease (AD). Acetylcholine contributes to localised arterial dilatation and increased cerebral blood flow (CBF) during neurovascular coupling via activation of endothelial nitric oxide synthase (eNOS). Decreased vascular reactivity is suggested to contribute to impaired clearance of $\beta$-amyloid $(A \beta)$ along intramural periarterial drainage (IPAD) pathways of the brain, leading to the development of cerebral amyloid angiopathy (CAA). However, the possible relationship between loss of cholinergic innervation, impaired vasoreactivity and reduced clearance of $A \beta$ from the brain has not been previously investigated. In the present study, intracerebroventricular administration of mu-saporin resulted in significant death of cholinergic neurons and fibres in the medial septum, cortex and hippocampus of C57BL/6 mice. Arterial spin labelling MRI revealed a loss of CBF response to stimulation of eNOS by the Rho-kinase inhibitor fasudil hydrochloride in the cortex of denervated mice. By contrast, the hippocampus remained responsive to drug treatment, in association with altered eNOS expression. Fasudil hydrochloride significantly increased IPAD in the hippocampus of both control and saporin-treated mice, while increased clearance from the cortex was only observed in control animals. Administration of mu-saporin in the TetOAPPSwelnd mouse model of AD was associated with a significant and selective increase in Aß40-positive CAA. These findings support the importance of the interrelationship between cholinergic innervation and vascular function in the aetiology and/or progression of CAA and suggest that combined eNOS/cholinergic therapies may improve the efficiency of A $\beta$ removal from the brain and reduce its deposition as CAA.
\end{abstract}

Keywords: Alzheimer's disease, Cholinergic, Clearance, eNOS, Vascular reactivity

\section{Introduction}

Increasing evidence suggests that structural and functional alterations of the cerebrovasculature contribute to the aetiology and/or progression of Alzheimer's disease (AD). In fact, vascular pathology has been suggested to

*Correspondence: c.hawkes@lancaster.ac.uk

${ }^{4}$ Department of Biomedical and Life Sciences, Lancaster University, Lancaster, UK

Full list of author information is available at the end of the article be one of the earliest indicators of the development of $\mathrm{AD}[38,39]$ and differential perfusion of $\mathrm{AD}$-sensitive brain areas such as the hippocampus, frontal and temporal lobes are present in people both with mild cognitive impairment and dementia $[2,18,34]$.

Cerebral amyloid angiopathy (CAA) is the most common form of cerebrovascular pathology in $\mathrm{AD}$ [42] and is characterised by the deposition of $\beta$-amyloid $(A \beta)$ peptides in the walls of cerebral arteries and capillaries [90]. While parenchymal plaques are made up predominantly

(c) The Author(s) 2021. This article is licensed under a Creative Commons Attribution 4.0 International License, which permits use, sharing, adaptation, distribution and reproduction in any medium or format, as long as you give appropriate credit to the original author(s) and the source, provide a link to the Creative Commons licence, and indicate if changes were made. The images or other third party material in this article are included in the article's Creative Commons licence, unless indicated otherwise in a credit line to the material. If material is not included in the article's Creative Commons licence and your intended use is not permitted by statutory regulation or exceeds the permitted use, you will need to obtain permission directly from the copyright holder. To view a copy of this licence, visit http://creativeco mmons.org/licenses/by/4.0/. The Creative Commons Public Domain Dedication waiver (http://creativecommons.org/publicdomain/ zero/1.0/) applies to the data made available in this article, unless otherwise stated in a credit line to the data. 
of $A \beta 42, A \beta 40$ is more commonly observed in CAA. CAA develops topographically, presenting initially in the occipital lobe, followed by the temporal, frontal and parietal lobes, then in the hippocampus and entorhinal cortex at later stages $[5,83,84]$. In addition to causing dysfunction and death of mural and endothelial cells, recent studies suggest that CAA contributes to impaired hemodynamic responses in both individuals with $\mathrm{AD}$ and people with hereditary CAA $[4,63,77,87,94]$.

A key pathological feature of sporadic CAA is a failure of clearance of $A \beta$ from the brain, which is mediated via enzymatic degradation, uptake in microglia and astrocytes and transcytosis across the blood-brain barrier [54, $55,93] . A \beta$ is also removed from the brain along the walls of the capillaries and arteries via intramural periarterial drainage (IPAD) and/or glymphatic drainage [7, 36, 56].

The IPAD hypothesis of $A \beta$ clearance is based in part on experimental observations that nanoparticles, solutes and $A \beta$ injected into the interstitial fluid (ISF) of deep brain structures are transported along and localise to cerebrovascular basement membranes (CVBM) in cortical and leptomeningeal vessels [3, 13, 27-29]. In the mouse brain, this process occurs very rapidly, within 5-10 min of injection [8, 13, 27-29]. Since the pattern of distribution of solutes closely mimics that of $A \beta$ accumulation in CAA and other angiopathies [14, 41, 85], failure of IPAD is a key element of CAA pathology. However, as the movement of solutes along CVBMs is counter to the direction of blood flow, the driving force that underlies IPAD is still unknown. Recent mathematical modeling suggests that oscillating pulsatile flow generated by the focal contraction and relaxation of arteries drives IPAD [1] and this is supported by recent experimental data $[3,64,88]$. Localised arterial dilatation and contraction can occur both spontaneously (e.g. vasomotion) and in response to neuronal activity (e.g. neurovascular coupling, NVC) and both mechanisms have been shown to be decreased in $\operatorname{AD}[19,69,79]$.

Smooth muscle cells that regulate arterial contraction and contribute to the regulation of cerebral blood flow (CBF) in the cortex and hippocampus receive innervation from cholinergic neurons that originate in the basal forebrain. Release of acetylcholine (ACh) via stimulation of the basal forebrain or increasing cholinergic tone using acetylcholinesterase inhibitors (AChEIs) has been shown to increase CBF in the cortex and hippocampus [50, 72]. ACh induces vasodilation primarily by stimulating the production of nitric oxide (NO) via activation of endothelial nitric oxide synthase (eNOS) [23, 97], although stimulation of neuronal NOS (nNOS)-containing interneurons can also increase CBF $[15,89]$. ACh-induced activation of eNOS is mediated principally by binding to muscarinic receptors that stimulate calcium release and binding of calciumcalmodulin to eNOS [25]. ACh activation of eNOS can also occur via the insulin-receptor substrate/PI3K/Akt pathway [96] and stimulation of the PI3K/Akt/eNOS pathway by the selective Rho- associated, coiled-coil containing protein kinase (ROCK) inhibitor fasudil hydrochloride, has been shown to increase CBF in mice and humans [59, 68]. Although multiple downstream signalling pathways are regulated by ROCK activity [ 45 , 76], several studies have reported no effect of fasudil hydrochloride on cerebral haemodynamics in $\mathrm{eNOS}^{-1-}$ mice, suggesting that eNOS is the principal NOS isoform targeted by fasudil hydrochloride [68, 78].

Decreased expression of eNOS has been reported in the occipital cortex in $\mathrm{AD}$, an area of the brain that is hypoperfused in AD [12]. Conversely, eNOS and inducible NOS (iNOS) activity have been shown to be significantly increased in the temporal and frontal cortices of $\mathrm{AD}$ patients [20], in association with hyperperfusion of those areas [34]. Several recent studies have reported that endogenous CAA load is increased in eNOS-deficient mice in the absence of alterations in parenchymal $A \beta$ or increased $A \beta$ production $[6,81]$, suggesting that dysfunction of eNOS may also contribute to the aetiology of CAA and that this may be related to impairments in $A \beta$ clearance from the brain.

Loss of cholinergic neurons as an early pathological feature of AD has been known since the 1980s and underpins the rationale for the current clinical use of AChEIs for the treatment of $\mathrm{AD}[9,22,66]$. Two recent findings from the Alzheimer's Disease Neuroimaging Initiative have reported that vascular dysregulation is an early predictor of the progression to $\mathrm{AD}$ and that loss of volume in the basal forebrain precedes pathological changes in the entorhinal cortex of individuals who went on to develop AD [38, 73]. These findings suggest that the interplay between loss of cholinergic innervation and vascular dysfunction may be important in the aetiology of AD. However, although some pathological studies have examined cholinergic loss at the neurovascular unit under experimental conditions [61] and in $\mathrm{AD}$ [60], less has been done to directly investigate the functional outcome of perivascular cholinergic denervation. The aim of this study was to test the hypothesis that loss of cholinergic innervation decreases $\mathrm{CBF}$ and IPAD of $\mathrm{A} \beta$ from the cortex and hippocampus of wildtype mice, leading to increased CAA in the TetOAPPSweInd model of AD.

\section{Materials and methods \\ Animals}

C57BL/6 mice were bred at the Open University (OU, Milton Keynes, UK) and the University of Southampton 
(Southampton, UK). TetOAPPSweInd mice developed by Dr Joanna Jankowsky (Baylor College of Medicine, Texas, US) [40] were a generous gift from Dr JoAnne McLaurin (Sunnybrook Research Centre, Toronto, Canada) and were also bred on a C57BL/6 background. Food and water were provided ad libitum. All animal work was approved by the Animal Welfare and Ethics Research Boards (AWERB) at the OU, University of Southampton and UCL in accordance with Home Office regulations and project licences (PPL 70/8507 and PPL 30/3095) under the Animals (Scientific Procedures) Act 1986.

\section{Mu-Saporin administration}

8-10 week old male C57BL/6 mice and 4-month old male and female TetOAPPSweInd mice were used for saporin injections. Mice were anesthetised under isoflurane gas and placed into a stereotaxic frame (Kopf instruments, CA, USA). Analgesia was administered intraperitoneally (Carprieve, 5\% w/v, $0.32 \mathrm{ml} / \mathrm{kg}$, Norbrook, Northamptonshire, UK) and a topical anaesthetic (Cryogesic (ethyl chloride), Acorus Therapeutics Ltd, Chester, UK) was applied before making a midline incision. $0.5 \mu \mathrm{L}$ of musaporin $(0.596 \mu \mathrm{g} / \mu \mathrm{l}$, Advanced Targeting Systems, CA, USA) or $0.9 \%$ sterile saline was injected into the left and right lateral ventricles (coordinates from Bregma: $\mathrm{AP}=-0.4 \mathrm{~mm}, \mathrm{ML}=\mp 1.0 \mathrm{~mm}, \mathrm{DV}=-2.3 \mathrm{~mm}$ ) using a 33 gauge Hamilton syringe. Mice were able to selfadminister sugar free jelly containing Carprofen $(250 \mu \mathrm{g}$ in $500 \mu$ jelly, Zoetis, London, UK) for 1 week post-surgery. Animals were randomly assigned to receive either saline or saporin and all experimenters were blinded to treatment until statistical analysis.

\section{Immunohistochemistry}

45 days after surgery, mice were deeply anesthetised and perfused intracardially with $0.01 \mathrm{M}$ phosphate buffered saline (PBS) followed by $4 \%$ paraformaldehyde (PFA). Brains were post-fixed in 4\% PFA overnight, sectioned (20 $\mu \mathrm{m}$ thickness) using a cryostat and stored at $-20^{\circ} \mathrm{C}$. Details of primary and secondary antibodies used for immunohistochemistry are listed in Additional file 1: Table 1.

For enzyme-linked immunohistochemistry, sections were washed in $0.01 \mathrm{M} \mathrm{PBS}$, incubated with $3 \%$ hydrogen peroxide, rinsed in PBS and treated with $70 \%$ formic acid for $45 \mathrm{~s}$. Sections were then blocked in 15\% normal donkey or goat serum (NDS, Sigma-Aldrich, Dorset, UK), followed by incubation overnight at $4{ }^{\circ} \mathrm{C}$ with anti-A $\beta 40$ (1:100) or anti-A $\beta 42$ (1:100). The next day, sections were incubated with biotinylated anti-rabbit (1:400) and developed using glucose oxidase enhancement with DAB as chromagen (Sigma-Aldrich, Dorset, UK). The specificity of the anti-A $\beta 40$ and anti-A $\beta 42$ antibodies was verified by pre-absorbing purified human $A \beta 40$ peptide with the anti-A $\beta 40$ antibody (10:1 molar ratio) alone or in combination with the anti-A $\beta 42$ antibody for $1.5 \mathrm{~h}$ at RT before proceeding with tissue incubation and development as described above (Additional file 2: Fig. 1a-d). Photomicrographs were obtained using a Nikon Eclipse 80i light microscope (Nikon UK Limited, Surrey, UK) and images from the hippocampus and cortex $(n=6$ control and $\mathrm{n}=7$ saporin) were analysed using Fiji (NIH, Maryland, USA).

For single labelling immunofluorescence, sections were washed in 0.01 M PBS, blocked with serum and incubated overnight at $4{ }^{\circ} \mathrm{C}$ with anti-choline acetyltransferase (ChAT; 1:75), anti-p75NTR (1:350), anti-GFAP (1:500), anti-Iba1 (1:500) or anti-laminin (1:350). Sections were incubated with the appropriate fluorophoreconjugated secondary antibodies and coverslipped using Mowiol $^{\circledR}$ (Sigma, Dorset, UK) containing 0.1\% v/v Citifluor (Citifluor ltd, London, UK).

For multiple labelling fluorescent immunohistochemistry, sections underwent antigen retrieval (Additional file 1: Table 1) and were then incubated overnight at $4{ }^{\circ} \mathrm{C}$ with either i) anti-ChAT (1:75) and anti-p75NTR (1:400), or ii) with anti-NOS (1:200) or anti-eNOS (1:200) in combination with anti-GFAP (1:2000) or anti-Iba1 (1:500). Sections were then incubated for $2 \mathrm{~h}$ at RT with the appropriate fluorophore-conjugated secondary antibodies, washed in PBS and coverslipped as above. The specificity of the fluorescently-conjugated secondary antibodies was verified by omitting the primary antibodies (Additional file 2: Fig. 1e-h).

For all fluorescent imaging, photomicrographs were obtained using a Leica SP5 confocal microscope using the same gain and intensity and maximum projection images were exported to Adobe Photoshop 2020 or Fiji.

\section{Quantification of immunohistochemistry}

The density of ChAT staining (neuronal cell bodies or fibres) in each brain region was quantified from low magnification images by calculating the percentage area covered by staining using the "Analyze particle" function in Fiji (NIH. Maryland, USA). For quantification of staining in the hippocampus, overlapping images were stitched together and values from both the ipsilateral and contralateral hemispheres were averaged for each animal. For quantification of cortical images, six random non-overlapping images spanning the somatosensory cortex of the ipsilateral cortex to the somatosensory cortex of the contralateral cortex were captured and averaged per animal. A single low magnification image/animal was used to quantify ChAT staining in the medial septum. The percentage area containing microglia, astrocytes and blood vessels was also calculated using the "Analyze particle" 
function in Fiji. Additionally, for anti-laminin staining, in order to quantify density by vessel type, a mask was set to select capillaries $\left(0-100 \mu \mathrm{m}^{2}\right)$ or large-diameter vessels $\left(101 \mu \mathrm{m}^{2}\right.$-infinity) using images calibrated according to the scale bar. The degree of colocalization between ChAT and p75NTR and between e/NOS and laminin was determined from three images/region/animal taken at $\times 40$ magnification using Pearson's correlation coefficient (PCC, Coloc 2 plugin) in Fiji. For quantification of $A \beta$ staining, images from the hippocampus and cortex taken at $\times 4$ magnification were stitched together, images were converted to 8 bit greyscale images and the \% area covered by CAA and plaques were quantified separately in Fiji.

\section{Arterial spin labelling MRI}

Approximately 5 weeks after ICV injection, C57BL/6 mice that received saline $(n=7)$ or mu-saporin $(n=7)$ were transported to UCL Centre for Advanced Imaging and allowed to acclimate for 1 week before imaging. A 9.4 T VNMRS horizontal bore scanner (Agilent Inc., Santa Clara, CA, USA) with a $72 \mathrm{~mm}$ inner diameter volume coil and 2 channel array head coil (Rapid Biomedical, Columbus, OH, USA) was used for radio frequency transmission and signal detection. Mice were initially anaesthetised under $2 \%$ isoflurane in medical air and maintained under $1.5 \%$ during imaging. A rectal probe and a pressure pad (SA Instruments, Stony Brook, NY, USA) were used to measure core temperature and monitor respiration throughout the procedure. Heated water tubing and a warm air blower using a feedback system (SA Instruments, Stony Brook, NY, USA) was used to regulate the temperature of the mice to $37^{\circ} \mathrm{C}$. Following a 5 min acquisition of baseline $\mathrm{CBF}$, mice were administered $10 \mathrm{mg} / \mathrm{kg}$ Fasudil hydrochloride i.p. (Tokyo Chemical Industries, Tokyo, Japan) and re-imaged $10 \mathrm{~min}$ later for an additional $5 \mathrm{~min}$. At the end of the imaging experiments, mice were perfusion fixed with 4\% PFA and their brains collected for immunohistochemistry. A total of 15 brain image slices were acquired with a thickness of $1 \mathrm{~mm}$ and an 'in-plane' resolution of $0.28 \mathrm{~mm}$ per mouse per experiment. Statistical Parametric Mapping (SPM, http://www.fil.ion.ucl.ac.uk/spm/) was applied to perfusion-weighted acquired ASL images [91]. Acquired images were processed using a Matlab (Mathworks, MA, USA) customised script. Regions of interest (cortex and hippocampus) were then manually traced on a single slice and quantified using a Matlab script which converted pixel intensity into CBF (ml/100 g/min) [91].

\section{Western blotting}

45 days post-injection with saline $(\mathrm{n}=7)$ or mup75-saporin $(n=6), C 57 \mathrm{BL} / 6$ mice were given an overdose of sodium pentobarbitone and perfused with 0.01 M PBS. Brains were removed, dissected for hippocampus and cortex, snap frozen and stored at $-80{ }^{\circ} \mathrm{C}$ until use. Tissues were homogenised in RIPA lysis buffer (20 mM Tris pH 8.0, $0.15 \mathrm{M} \mathrm{NaCl}, 1.27 \mathrm{mM}$ EDTA, $1 \mathrm{ml}$ Igepal, $0.1 \% \mathrm{SDS}, 50 \mathrm{mM} \mathrm{NaF}, 1.48 \mathrm{mM} \mathrm{NaVO}_{3}$ containing 1:100 Protease inhibitor cocktail [Merck Millipore, UK]), centrifuged at $10,000 \mathrm{~g}$ at $4{ }^{\circ} \mathrm{C}$ for $10 \mathrm{~min}$ and the supernatant was collected. $30 \mu \mathrm{g}$ or $40 \mu \mathrm{g}$ of proteins were separated by gel electrophoresis and membranes were then blocked in $8 \%$ non-fat milk before incubation with anti-eNOS (1:5000, Cell Signalling Technology, London, UK) or anti-nNOS (1:250, Cell Signalling Technology) overnight at $4{ }^{\circ} \mathrm{C}$. Membranes were then washed in TBST before being incubated in HRP-conjugated anti-rabbbit (1:5000, Fisher Scientific) for $1 \mathrm{~h}$ at room temperature and developed using an enhanced chemiluminescence kit (GE Healthcare, Little Chalfont, UK). Membranes were then stripped and re-probed with antiGAPDH (1:50,000, Sigma-Aldrich) to ensure equal protein loading. Optical density of the bands was quantified and normalised to GAPDH levels using Fiji.

\section{Assessment of IPAD}

45 days after injection with saline or saporin, mice were anesthetised with isoflurane and placed into a stereotaxic frame. For hippocampal injections, $0.5 \mu \mathrm{L}$ of $50 \mu \mathrm{M}$ human A $\beta 40$ Hilyte Fluor ${ }^{\mathrm{TM}} 555$ (AnaSpec, California, USA) was injected into the left hippocampus (coordinates from Bregma: $\mathrm{AP}=-1.9 \mathrm{~mm}, \mathrm{ML}=1.5 \mathrm{~mm}$, $\mathrm{DV}=-1.7 \mathrm{~mm}, \mathrm{n}=16$ control and $\mathrm{n}=14$ saporin). Mice were perfused with PBS and 4\% PFA 5 min post-injection. For cortical injections, control $(\mathrm{n}=8)$ and saporin $(\mathrm{n}=7)$ mice were injected with $0.25 \mu \mathrm{L}$ of $50 \mu \mathrm{M}$ A $\beta 40$ HiLyte Fluor $^{\mathrm{TM}} 555$ into the right cortex (co-ordinates from Bregma $\mathrm{AP}=-2 \mathrm{~mm}, \mathrm{ML}=-1.5 \mathrm{~mm}, \mathrm{DV}=-0.5 \mathrm{~mm}$ ) and mice were perfused $2.5 \mathrm{~min}$ later. All injections were carried out at a rate of $0.2 \mu \mathrm{L} / \mathrm{min}$ using a 33 gauge Hamilton syringe and the injection needle was left in situ for 2 min to avoid reflux. A separate group of control and saporin-treated mice ( $n=5 /$ group) were administered fasudil hydrochloride $(10 \mathrm{mg} / \mathrm{kg}$, i.p. $) 10 \mathrm{~min}$ before intracerebral injections. Tissue sections were processed for double-labeling immunohistochemistry as described above using anti-laminin (1:350) and anti- $\alpha$ smooth muscle actin conjugated to FITC (1:350; Additional file 1: Table 1). Brain sections that were $\geq 400 \mu \mathrm{m}$ away from the site of injection were imaged for quantification. The number of capillaries, arteries and veins that contained A $\beta 40$ Hilyte Fluor ${ }^{\mathrm{TM}} 555$ within each image were counted manually and divided by the total area analysed, as described previously [27, 29, 61]. 


\section{Statistical analysis}

Data were tested for normality using the Shapiro-Wilk test and the ROUT test was used to identify and remove statistical outliers. Comparisons between control and saporin-treated mice were analysed using two-tailed Student's $t$ test or Mann-Whitney $U$ test where data were not normally distributed. Analysis of baseline vs stimulated CBF was carried out using paired one-tailed t-test and Wilcoxon matched-pairs signed rank test. Differences in NOS activity were analysed using one-way ANOVA with Sidak post hoc test. Differences in counts of A 340 -positive vessels within each brain region were analysed using a one-way ANOVA with Sidak post hoc analysis or Kruskal-Wallis test with Dunn's post hoc. In all cases, significance was set at $p<0.05$ and data are displayed as mean $\pm S E M$.

\section{Results}

mu-Saporin induces loss of cholinergic neurons and fibres In control mice, immunohistochemistry for ChAT labelled neurons in the medial septum (MS), diagonal band of Broca (DBB) and striatum (Fig. 1a). ChATpositive fibres in the hippocampus and cortex were also observed in these animals (Fig. 1b, c). Colocalization was noted between ChAT and p75NTR in the majority of basal forebrain neurons $(\mathrm{PCC}=0.68)$ as well as in fibre projections in the hippocampus and cortex $(\mathrm{PCC}=0.25$ and 0.24 , respectively) in control animals (Additional file 3: Fig. 2). Administration of mu-saporin induced a significant loss of ChAT-positive, p75NTR-positive neurons in the MS and DBB (Fig. 1d, g, Additional file 3: Fig. 2), as well as fibres in the hippocampus (Fig. 1e, h, Additional file 3: Fig. 2) and cortex (Fig. 1f, i, Additional file 3: Fig. 2), confirming the usefulness of the model to induce significant death of basal forebrain cholinergic neurons and their projection fibres.

\section{Cholinergic loss decreases eNOS-mediated cerebral blood flow in the cortex but not the hippocampus}

We have previously found that mu-saporin causes loss of cholinergic innervation of cerebral blood vessels and that this denervation is more pronounced in the cortex than the hippocampus [61]. To assess the effect of this loss on baseline and evoked CBF, arterial spin labelling MRI was used to image cerebral perfusion in the hippocampus and cortex of control and saporin-treated mice. Baseline CBF did not differ between control and saporin mice in either the hippocampus or cortex (Fig. 2a, b). Administration of fasudil hydrochloride caused a significant increase in hippocampal CBF relative to baseline in both control and saporin-treated mice (Fig. 2a). The degree of CBF increase was similar between treatment groups (Fig. 2 a). In the cortex, fasudil hydrochloride induced a significant increase in $\mathrm{CBF}$ in the control, but not the saporin group compared to baseline (Fig. 2b). In addition, control mice that were administered fasudil hydrochloride had a significantly higher CBF compared to saporin-treated mice given the drug (Fig. 2b). These results suggest that denervated hippocampal vessels were still responsive to eNOS stimulation, while cortical vessels were not.

\section{eNOS protein expression in the hippocampus and cortex is differentially affected by saporin treatment}

To determine whether regional differences in the responsiveness to fasudil hydrochloride were due to differences in the levels of NOS expression, cortical and hippocampal tissues were assessed by Western blotting using eNOS and nNOS-specific antibodies. eNOS expression was significantly higher in the hippocampus of saporintreated mice compared to controls (Fig. 3a), while no statistically significant differences were observed between control and saporin mice in the cortex (Fig. 3b). Levels of nNOS did not differ significantly between control and saporin-treated mice in either the hippocampus or cortex (Fig. 3c, d). To determine if NOS expression may have been influenced by possible differences in vessel densities, the vascular expression of NOS in laminin-positive vessels was quantified in control and saporin tissues (Fig. 3e-h). Quantification of the NOS-to-laminin ratio confirmed the significant decrease in NOS expression in the cortex of saporin-treated mice (Fig. 3m). However, the NOS ratio in the hippocampus did not differ significantly between control and saporin mice (Fig. $3 \mathrm{~m}$ ). We also observed some NOS expression in glial cells in the hippocampus of saporin-treated mice. To determine if the increased eNOS expression detected by Western blot was due to expression in glial cells, hippocampal sections were stained with anti-eNOS and anti-GFAP or antiIba1 (Fig. 3i-l). These results confirmed minimal expression of eNOS in astrocytes, but some colocalization of eNOS with Iba1-positive microglia, which was higher in saporin-treated mice, although this did not reach statistical significance ( $p=0.13$, Fig. $3 n)$. These results suggest that levels of eNOS are downregulated in the cortex, and upregulated in the hippocampus of saporin-treated mice and that increased eNOS expression in the hippocampus may be due in part to upregulation by microglia.

\section{Administration of fasudil hydrochloride increases IPAD in the hippocampus but not cortex of denervated mice}

Our previous work has shown that saporin treatment significantly decreases cholinergic innervation of arterial smooth muscle cells in the hippocampus and cortex [61]. In vitro modelling supports the hypothesis that the localised arterial pulsations that regulate CBF [32] also provide the principle driving force for solute clearance from 


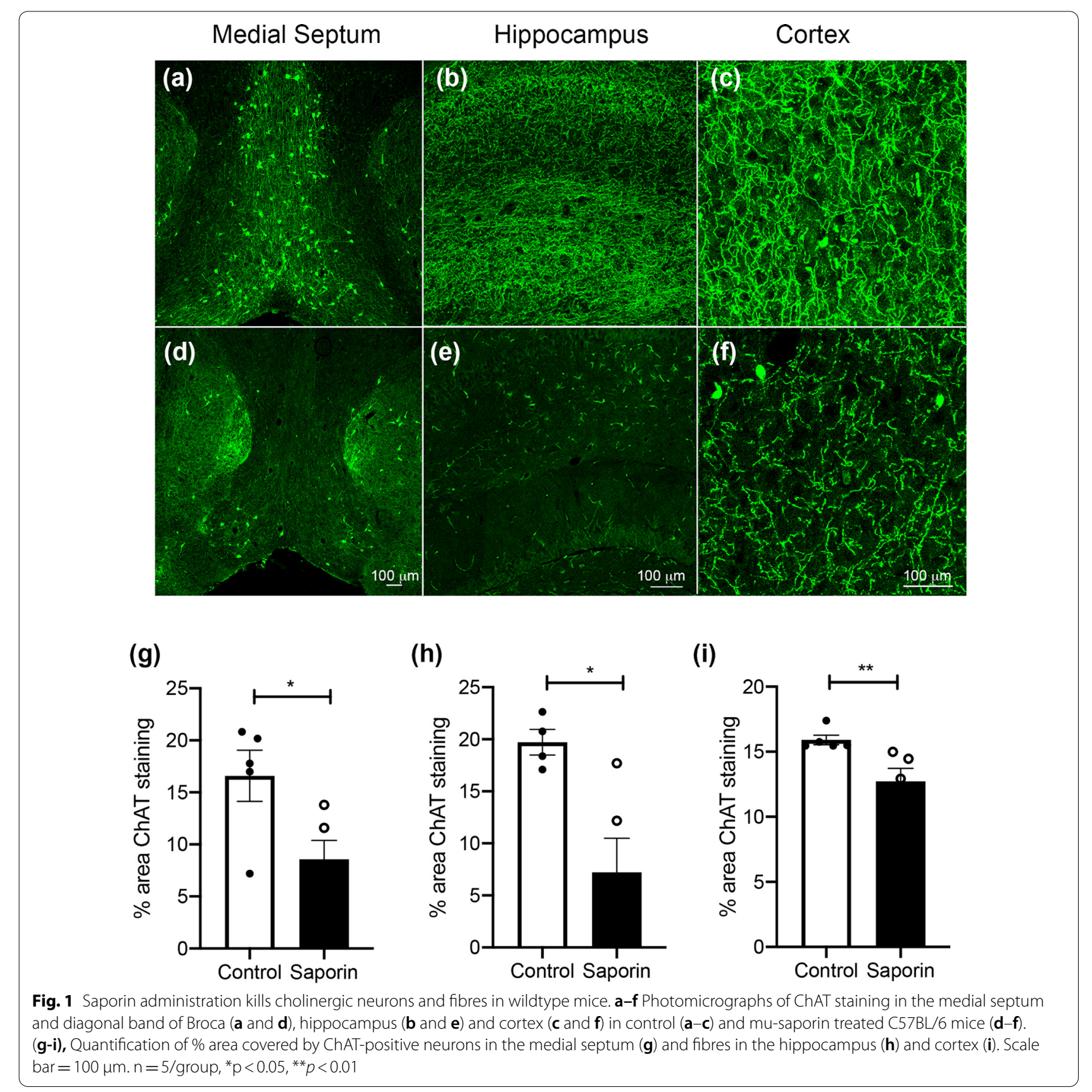

the brain via IPAD [1]. To determine if loss of cholinergic innervation altered IPAD, the pattern of distribution of human A 340 -AF555 was evaluated following injection into the hippocampus or cortex of control and saporintreated $\mathrm{C} 57 \mathrm{Bl} / 6$ mice under physiologic and stimulated conditions. Triple-labelling immunohistochemistry demonstrated the presence of A $\beta 40-A F 555$ primarily in capillaries and arteries in both the hippocampus and cortex (Fig. 4a-f). Quantification of the number of hippocampal blood vessels that contained $A \beta$ showed no difference between control and saporin-treated mice under baseline physiological conditions (Fig. 4c). Administration of fasudil hydrochloride resulted in significantly more $A \beta$-positive blood vessels in both control and 

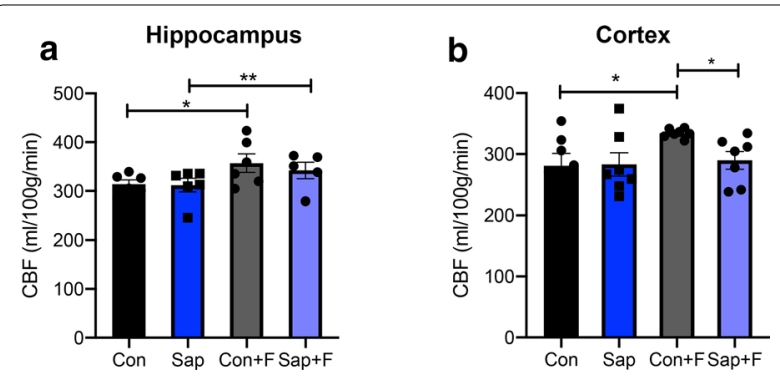

Fig. 2 The hippocampus, but not cortex, of denervated mice remains responsive to eNOS-stimulated increase in CBF. $\mathbf{a}$ and $\mathbf{b}$ Quantification of cerebral blood flow (CBF) in the hippocampus (a) and cortex (b) of control (con) and saporin-treated mice (sap) at baseline and 10 min after administration of fasudil hydrochloride $(+F)$, averaged over 5 min. $n=5-7 /$ group, ${ }^{*} p<0.05$

saporin animals compared to baseline (Fig. 4b, c). However, fasudil treatment did not affect hippocampal vessel counts between control vs. saporin mice (Fig. 4c).

Preliminary assessment of IPAD in the cortex using the same parameters as those in the hippocampus (e.g. $0.5 \mu \mathrm{L}$ A 340 -AF555+5 min clearance) revealed a much smaller bolus of $A \beta$ at the site of injection and very few $\mathrm{A} \beta$-positive vessels were visible at $400 \mu \mathrm{m}$ away from the injection site compared to the hippocampus (Additional file 4: Fig. 3a and b). Following a series of modifications (Additional file 4: Fig. 3c-e), the injection protocol for cortical injections was adapted to $0.25 \mu \mathrm{L}$ A 340 -AF555 with 2.5 min post-injection time (Fig. $4 \mathrm{~d}-\mathrm{f}$ ), to allow for sufficient numbers of A $\beta 40$-positive vessels to be counted. Similarly to the hippocampus, quantification of cortical vessels that contained $A \beta$ revealed no baseline differences between control and saporin-treated mice (Fig. 4f). In control animals, administration of fasudil hydrochloride resulted in significantly fewer A 340 -containing vessels (Fig. 4d-f). Although a similar trend was observed in saporin animals, the difference was not statistically significant $(p=0.08)$ and no difference was observed between control + fasudil and saporin + fasudil groups (Fig. 4f).

To determine if IPAD may have been influenced by differences in vessel number and/or microglia and astrocyte activation, densities of each were quantified in control and saporin-treated mice. The density of laminin-positive macrovessels and capillaries did not differ between control and saporin-treated mice in either the cortex or hippocampus (Fig. $4 \mathrm{~g}-\mathrm{j}$ ), although capillary density was significantly higher in the cortex than the hippocampus in both treatment groups $(p=0.003)$. Similarly, quantification of Iba1 and GFAP staining revealed no effect of saporin treatment on astrocyte or microglial coverage of the hippocampus or cortex (Additional file 4: Fig. 3f-k).
These findings confirm that IPAD was not affected by differences in vessel density or glial activation and indicate that clearance of $A \beta$ was stimulated by fasudil hydrochloride and that this responsiveness remains intact in the hippocampus, but not the cortex of denervated mice.

\section{Loss of cholinergic innervation increases CAA in the hippocampus of TetO-APP mice}

To evaluate if cholinergic denervation potentiated $A \beta$ pathology, 4-month old TetO-APPSweInd mice were administered saline or mu-saporin. Unexpectedly and in contrast to the observations made in the C57BL/6 mice, no significant differences were noted in the number of ChAT-positive neurons in the medial septum between control and saporin-treated mice (Fig. 5a, d, g). Significantly fewer cholinergic fibres were observed in the hippocampus of saporin vs control mice (Fig. 5b, e, h), while ChAT fibre density in the cortex was also unaffected by saporin treatment (Fig. 5c, f, i). To determine if the attenuated effect of saporin in the TetOAPPSweInd mice was due to endogenous differences in ChAT and p75NTR expression, fibre appearance and density was compared between TetO-APPSweInd mice and wildtype littermates. The morphology of fibres in the TetO-APPSweInd appeared dystrophic, with swollen varicosities and shorter processes than that of cholinergic fibres in the wildtype mice (Figs. 1b, c, 5b, c). The density of ChAT-positive neurons in the MS was significantly higher in TetO-APPSweInd mice compared to wildtype animals, although no differences in hippocampal or cortical ChAT fibre density were observed between strains (Fig. 5j). Analysis of p75NTR expression showed significantly lower receptor expression in the hippocampus of TetO-APPSweInd mice compared to wildtypes, while no differences were observed in the cortex or MS (Fig. 5k). Additional analysis found that the ratio of p75NTR to ChAT expression was significantly lower in the MS and hippocampus of TetO-APPSweInd mice compared to wildtype animals (Fig. 5l).

Quantification of $\mathrm{A} \beta$ pathology in the hippocampus after saporin treatment showed no difference in the percentage area covered by A 340 -positive plaques between control and saporin mice (Fig. 6a, b, e). However, A 340 CAA load was significantly higher in the saporin-treated mice (Fig. 6a, b, e). A similar but non-significant pattern of vascular $A \beta 42$ staining was observed between control and saporin mice, while parenchymal A $\beta 42$ was not affected by saporin treatment (Fig. 6a, b, f). In the cortex, no differences were observed between control and saporin-treated mice in the density of A 340 -positive 

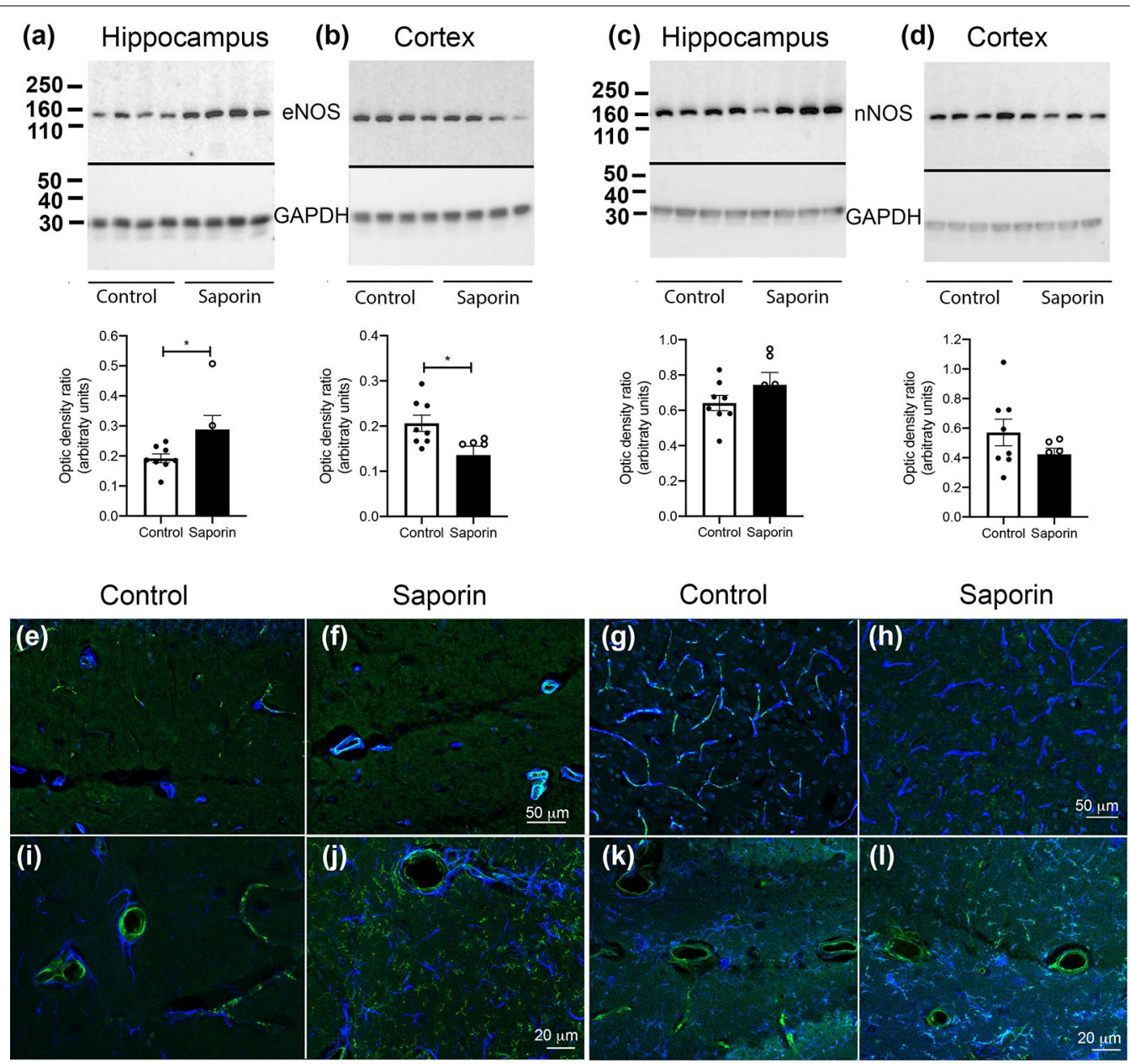

(m) NOS:laminin ratio

(n) Colocalisation with eNOS
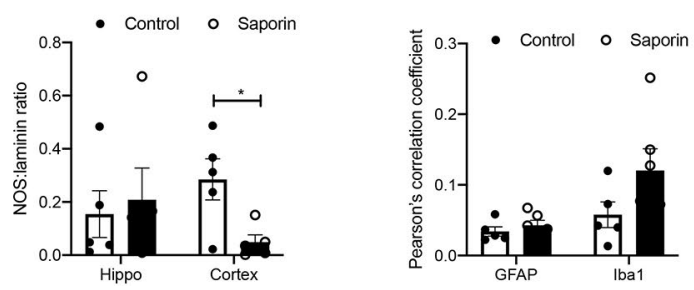

Fig. 3 Regional variation in NOS expression and activity in control and saporin-treated mice. a-d Western blots and quantification of levels of eNOS ( $a$ and $b$ ) and $n \operatorname{NOS}$ (c and $\mathbf{d}$ ) in the hippocampus (a, c) and cortex (b, d) of control and saporin-treated mice $(n=6-8 /$ group). Molecular weight markers $(\mathrm{kDa})$ are shown on the right hand side. The black line demarcates the original blot (upper) and the same blot re-probed for loading control (lower). $\mathbf{e}-\mathbf{h}$ Photomicrographs showing the expression of total NOS (green) in laminin-positive vessels (blue) in the hippocampus (e and $\mathbf{f}$ ) and cortex ( $\mathbf{g}$ and $\mathbf{h}$ ) of control (e and $\mathbf{g}$ ) and saporin-treated mice ( $\mathbf{f}$ and $\mathbf{h}$ ). Note the stable expression of NOS in hippocampal vessels of saporin-treated mice, while NOS expression is significantly reduced in cortical vessels of saporin animals. i-l eNOS expression (green) in GFAP-positive astrocytes (blue, $\mathbf{i}$ and $\mathbf{j}$ ) and Iba1-positive microglia (blue, $\mathbf{k}$ and $\mathbf{I}$ ) in the hippocampus of control (i and $\mathbf{k}$ ) and saporin mice ( $\mathbf{j}$ and $\mathbf{I}$ ). Colocalization between eNOS and GFAP or Iba-1 is shown as white-turquoise. $\mathbf{m}$ and $\mathbf{n}$ Quantification of NOS expression in blood vessels as a ratio to overall vessel density $(\mathbf{m})$ and degree of colocalisation between eNOS and GFAP or Iba1 as measured by the Pearson's correlation coefficient (n). $n=5$ /group. Scale bars for $f$ and $h=50 \mu m ; j$ and $I=20 \mu m .{ }^{*} p<0.05$ 

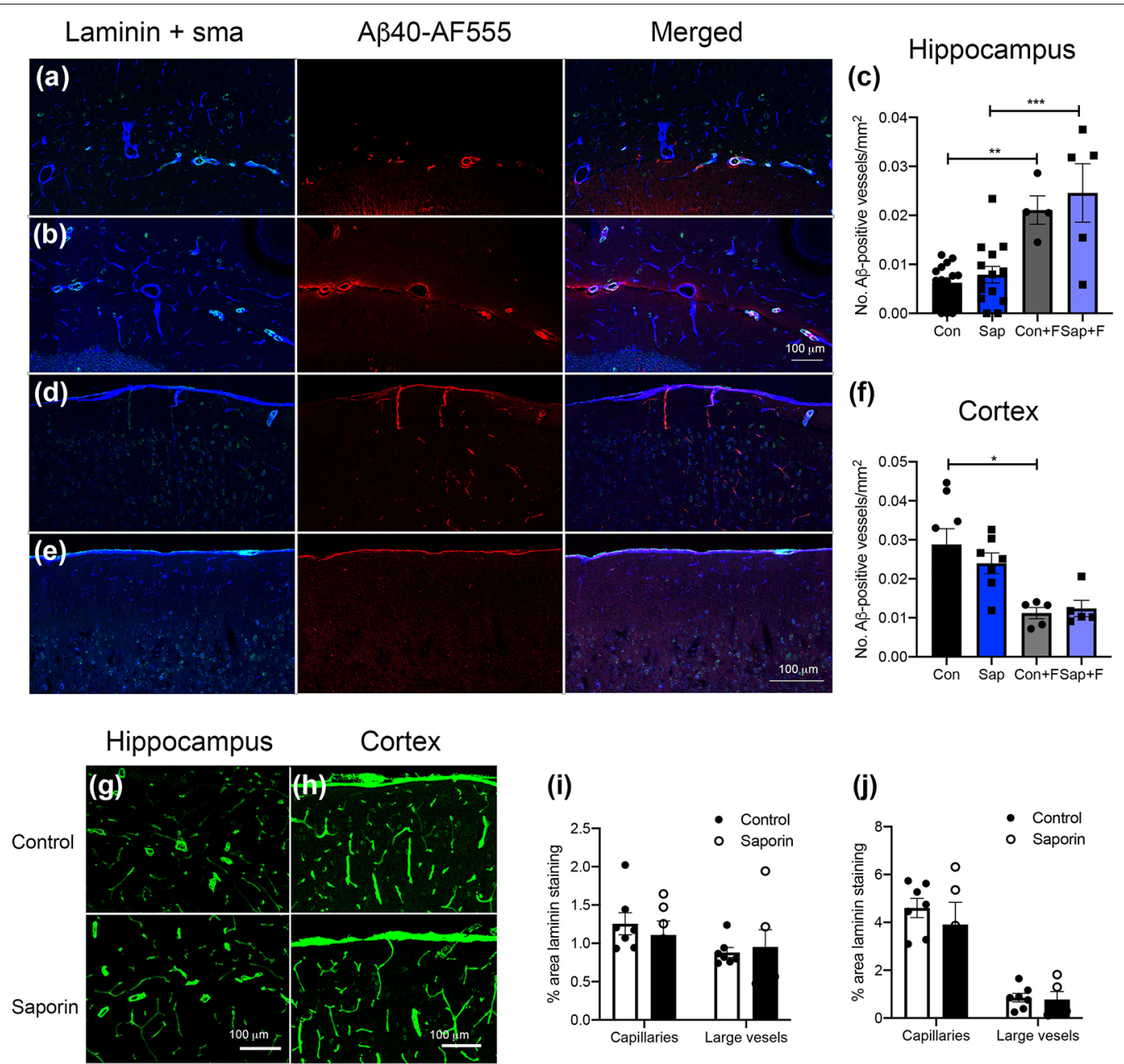

Fig. 4 Administration of fasudil hydrochloride increases IPAD in the hippocampus, but not cortex of denervated mice. a-f Photomicrographs showing the distribution of human Aß40-AF555 (red) at 5 min post-injection into the hippocampus (a and $\mathbf{b}$ ) and at 2.5 min after injection into the cortex ( $\mathbf{d}$ and $\mathbf{e}$ ) of control mice at baseline ( $\mathbf{a}$ and $\mathbf{d}$ ) and after administration of fasudil hydrochloride (b and $\mathbf{e}$ ). The cerebrovascular basement membrane was labelled with anti-laminin (blue) and smooth muscle cells were identified with anti-a smooth muscle actin (green). Quantification of the total number of A 340 -containing vessels in the hippocampus (c) and cortex (f) of control (con) and saporin (sap)-treated mice at baseline ( $n=14-16$ for hippocampus and $n=7-8$ for cortex) and after fasudil hydrochloride ( $+F)$ ( $n=5 /$ group for both regions). $\mathbf{g}$ and $\mathbf{h}$ Photomicrographs of laminin staining in the hippocampus ( $\mathbf{g}$ ) and cortex (h) of control (upper panels) and saporin-treated mice (lower panels). $\mathbf{i}$ and $\mathbf{j}$ Quantification of $\%$ area covered by laminin in the hippocampus (i) and cortex (j) of control and saporin animals. $n=5-7 /$ group. Scale bars $=100 \mu m .{ }^{*} p<0.05$, ${ }^{* *} p<0.01,{ }^{* * *} p<0.001$

plaques or CAA (Fig. 6c, d, g). Likewise, the density of cortical parenchymal and vascular A 442 was unaffected by saporin treatment (Fig. 6c, d, h).

As with the C57BL/6 mice, vessel density between control and saporin-treated TetO-APPSweInd mice was similar in both the cortex and hippocampus (Fig. 6i-l). Analysis of GFAP and Iba1 expression revealed no significant difference in area coverage between treatment groups in either brain region (Additional file 4: Fig. 3l-q). These findings confirm that saporin administration did not significantly alter vessel density or glial activation in the TetO-APP mice and support a role for loss of cholinergic innervation in potentiating CAA pathology.

\section{Discussion}

Results from this study suggest that loss of cholinergic innervation differentially affects cortical and hippocampal responsiveness to eNOS-stimulated increases in $\mathrm{CBF}$ and IPAD in wildtype mice, with hippocampal, but not cortical, vessels remaining responsive to stimulation. The death of cholinergic nerve fibres resulted in a significant and selective increase in AB40-positive CAA in the TetO-APPSweInd model of $\mathrm{AD}$. These findings support the importance of the interrelationship between cholinergic innervation and vascular function in the aetiology and/or progression of CAA and suggest that regional vulnerability or resilience 

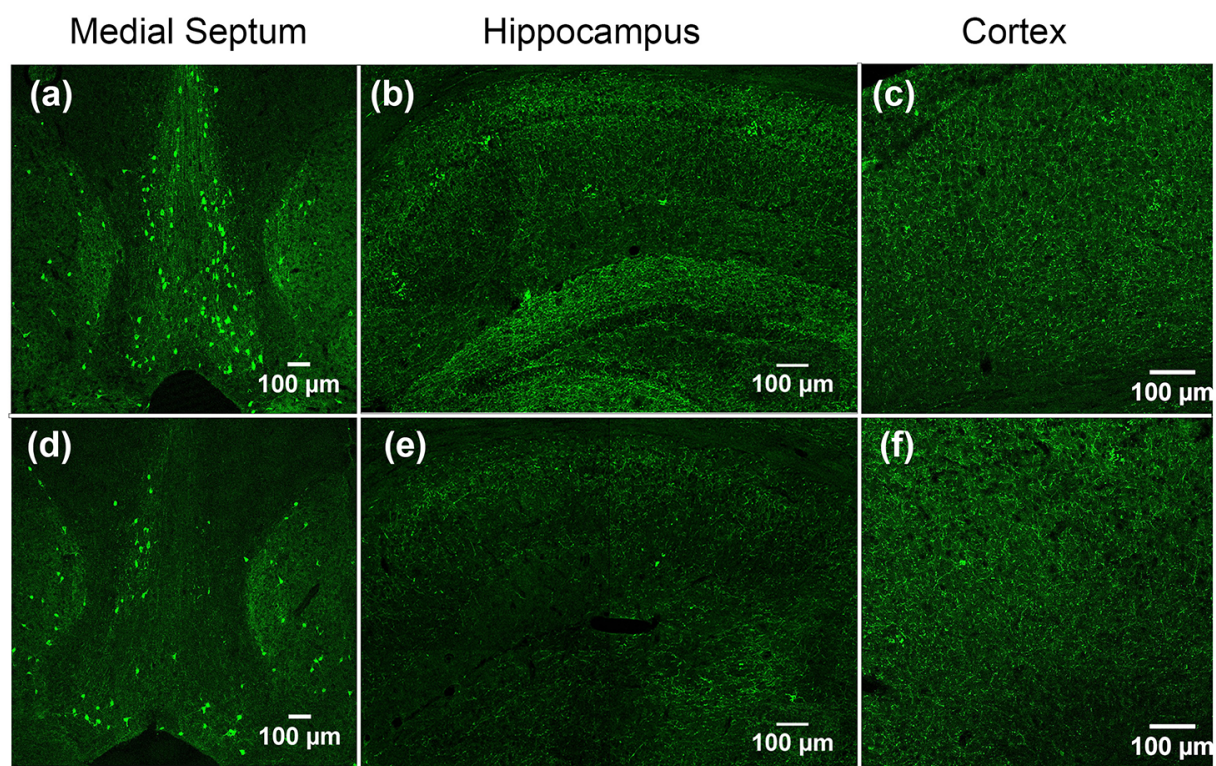

(e)

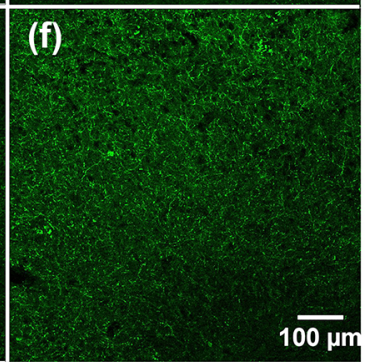

(g)

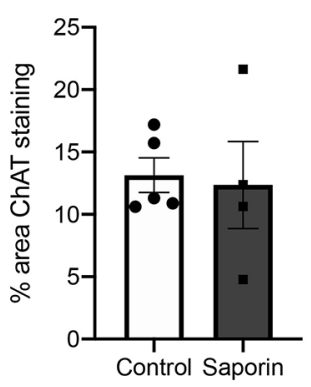

(j)

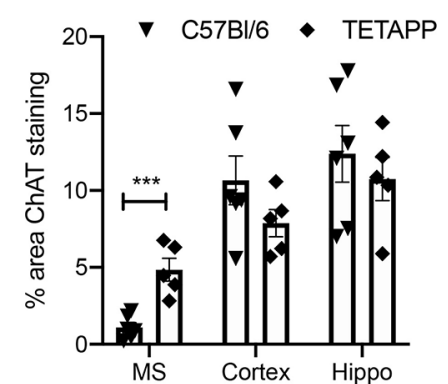

(h)

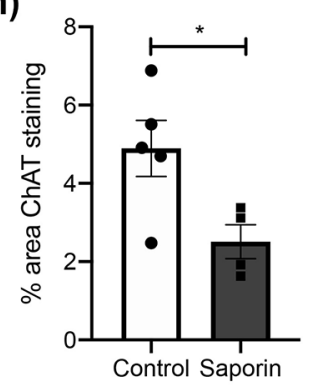

(k)

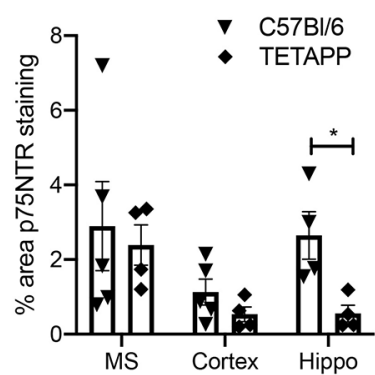

(i)

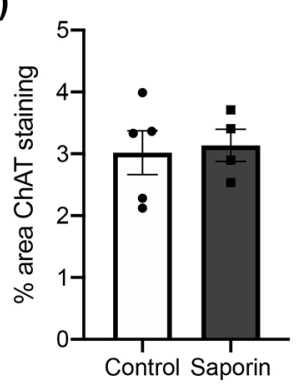

(l)

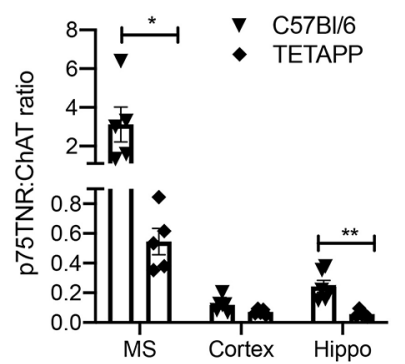

Fig. 5 Distribution and quantification of cholinergic and p75NTR-positive neurons in control and saporin-treated TetO-APPSwelnd mice. a-f Photomicrographs of ChAT staining in the medial septum and Diagonal band of Broca (a and $\mathbf{d}$ ), hippocampus (b and $\mathbf{e}$ ) and cortex (c and $\mathbf{f}$ ) in control (a-c) and mu-saporin treated (d-f) TetO-APPSwelnd mice. ( $\mathbf{g}-\mathbf{i})$, Quantification of $\%$ area covered by ChAT-positive neurons in the medial septum $(\mathbf{g})$ and fibres in the hippocampus $(\mathbf{h})$ and cortex (i), $n=4-5 /$ group. $\mathbf{j}-\mathbf{I}$ Quantification of $\%$ area covered by ChAT (j) and p75NTR-positive (k) neurons and fibres and the ratio of ChAT:p75NTR expression (I) in the medial septum (MS), hippocampus (Hippo) and cortex of C57BL/6 and TetO-APPSwelnd (TETAPP) mice, $n=5 /$ group/strain. Scale bar $=100 \mu \mathrm{m} .{ }^{*} p<0.05,{ }^{* *} p<0.01,{ }^{* * *} p<0.001$

to loss of cholinergic dysfunction may contribute to the topographical nature of CAA (Additional file 4: Fig. 3).

Degeneration of cholinergic neurons and shrinkage of the basal forebrain are early features of $\mathrm{AD}$ and are associated with increased $A \beta$ pathology, altered $\mathrm{CBF}$ and cognitive impairment $[9,22,26,82,86]$. In agreement with previous studies $[58,61]$, we found that intracerebral administration of mu-saporin, which selectively targets p75NTR-expressing neurons, caused the death of ChAT-positive neurons in the MS as well as their fibre 

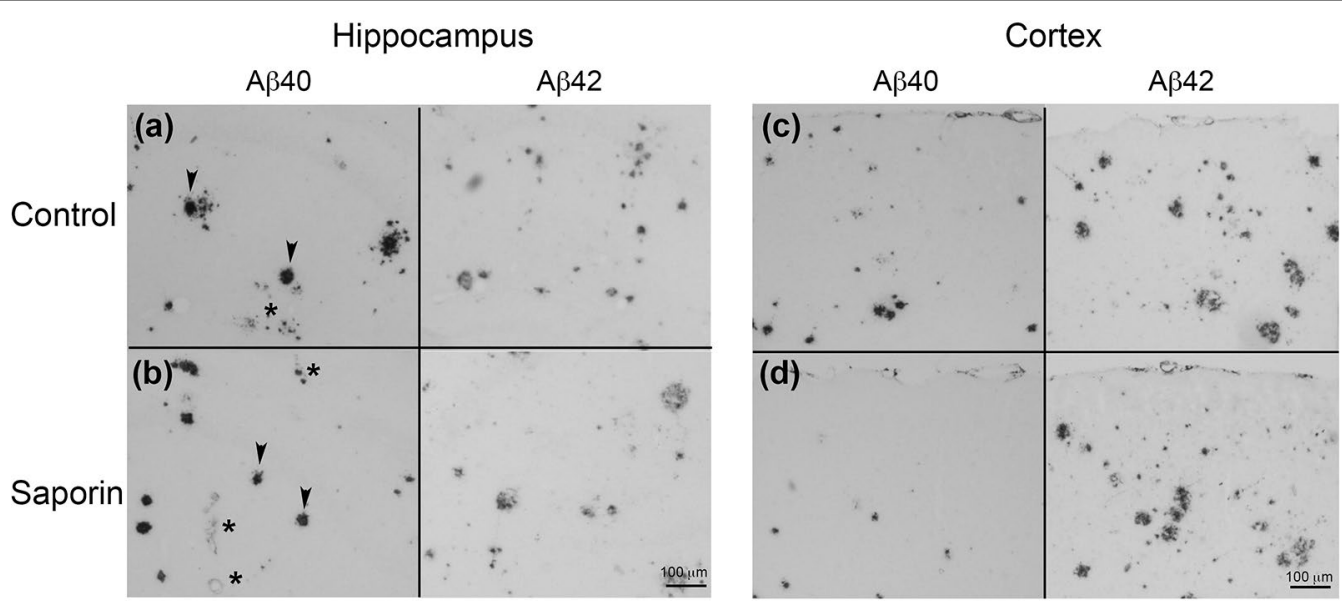

(e)

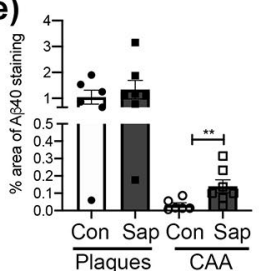

(f)

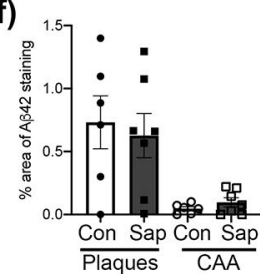

(g)

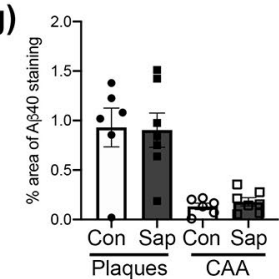

(h)

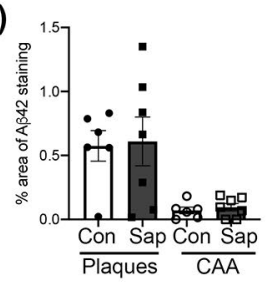

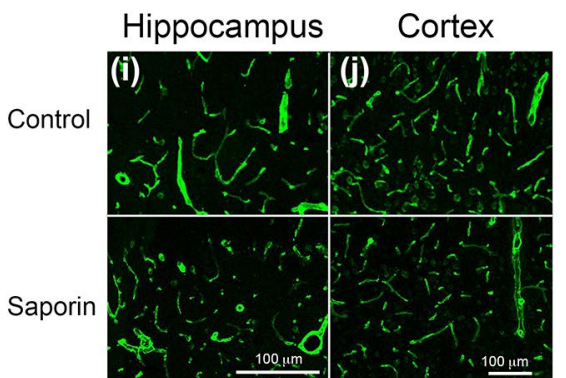

(k)

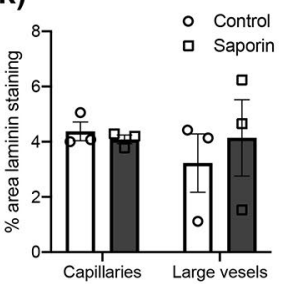

(I)

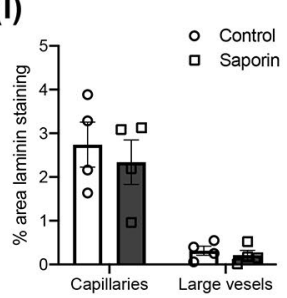

Fig. 6 Loss of cholinergic innervation selectively increases A 340 -positive CAA in the hippocampus of TetO-APP mice. a-h Photomicrographs of hippocampal (a and $\mathbf{b}$ ) and cortical tissues (c and d) of TetO-APP mice stained with antibodies against human A 40 (a-d, left panels) and Aß42 staining (a-d, right panels). Tissues from control animals are shown in the upper panels and saporin-treated tissues are shown in the lower panels. Arrowheads show plaques and asterisks show CAA-positive vessels. e-h Quantification of \% area covered by A 40 (e and $\mathbf{g}$ ) and Aß42-positive ( $f$ and $\mathbf{h}$ ) plaques and blood vessels in the hippocampus (e and $\mathbf{f}$ ) and cortex ( $\mathbf{g}$ and $\mathbf{h}$ ) of TetO-APPSwelnd mice, $\mathrm{n}=6-7 /$ group. $\mathbf{i}-\mathbf{I}$ Photomicrographs of laminin staining in the hippocampus (i) and cortex (j) of control (upper panels) and saporin-treated mice (lower panels). k Histogram showing quantification of laminin density in control and saporin-treated mice. $n=3-5 /$ group. Scale bars $=100 \mu \mathrm{m} .{ }^{* *} p<0.01$

projections in the cortex and hippocampus of wildtype mice.

ACh has a well-known vasodilatory effect in the brain and stimulation of the basal forebrain leads to increased cortical CBF [33, 35]. This effect is predominantly observed during NVC when release of ACh stimulates the production of NO via activation of eNOS or indirectly by stimulation of nNOS-containing interneurons [53]. Although ASL MRI can be used to measure NVC in the cortex using whisker or forepaw stimulation [49], to our knowledge similar methods are not available to stimulate NVC in the hippocampus of anesthetised animals.
Therefore, to evaluate the impact of loss of cholinergic innervation on evoked CBF, we mimicked ACh activation of eNOS by using the selective ROCK inhibitor fasudil hydrochloride, which has been shown to increase CBF by stimulating the PI3K/Akt/eNOS pathway [68, 76]. Consistent with previous reports [50], loss of cholinergic innervation in the cortex and hippocampus did not affect baseline CBF in either region, supporting a primary role of ACh on CBF during NVC. However, while administration of fasudil hydrochloride was not able to evoke a change in $\mathrm{CBF}$ in the cortex of saporin-treated mice, 
denervated vessels in the hippocampus remained responsive to stimulation.

Because multiple downstream signalling pathways in addition to eNOS are regulated by ROCK activity, including those relating to smooth muscle contraction [45], we cannot definitively conclude that the observed effects were due to stimulation of eNOS. However, the findings that levels of eNOS were significantly decreased in the cortex and increased in the hippocampus of saporintreated mice, support the hypothesis that loss of cholinergic innervation resulted in opposing effects on eNOS expression that aligned with the CBF response. Although eNOS is principally expressed by endothelial cells, previous studies have reported its expression in neurons, astrocytes and in microglia across various species $[16,75$, 92]. Our observation that eNOS was expressed not only in blood vessels but also by microglia in the hippocampus of saporin-treated mice, suggests that the functional effects of fasudil hydrochloride in the hippocampus may also be due in part to activation of non-vascular cells. Although it is not clear why the effect of saporin treatment induced an opposite expression of eNOS between the cortex and hippocampus, endogenous NOS activity in both the nNOS- and eNOS-enriched fractions has previously been reported to be higher in the hippocampus compared to the cortex [74]. This is supported by previous reports showing that changes in $\mathrm{CBF}$ in the hippocampus were more proportional to changes in nNOS activity than in the cortex [52] and that the cortex is more sensitive than the hippocampus to inhibition of nNOS activity [43].

Previous studies have suggested that contractions of arterial smooth muscle cells are required for drainage of fluid along cerebral blood vessels [1, 3, 37], although whether this pulsation is sufficient to drive bulk flow of ISF and CSF remains controversial [11, 31]. Several studies have shown that vasoreactivity in AD is improved following treatment with AChEIs [71]. We hypothesised that there is a direct relationship between vasoreactivity and the efficiency of IPAD and that loss of cholinergic innervation would impair IPAD of $A \beta$ in a similar pattern to that observed for CBF. No differences in IPAD were observed between control and saporin-treated mice in either brain region under baseline physiological conditions. Our observation that fewer $A \beta$-positive vessels were visible in the cortex after a 5 min diffusion period compared to the hippocampus, suggests that IPAD of A $\beta$ may be endogenously faster in the cortex than in the hippocampus. We have previously reported differences in the efficiency of IPAD between subcortical brain regions that are differentially affected by CAA [27]. However, given the relatively small thickness of the mouse cortex [65], it is possible that the depth of injection into the cortex (0.5 $\mathrm{mm}$ from dura) may have flooded the subarachnoid space, even when using the smaller $0.25 \mu \mathrm{L}$ volume. Therefore, more detailed in vivo tracer experiments are needed to clarify rates of IPAD between cortical and hippocampal regions. However, in agreement with other studies [21, 62], we also found that cerebrovascular density was significantly higher in the cortex compared to the hippocampus. This larger surface area may allow for solutes contained within the ISF to be more rapidly removed from the cortex than from the hippocampus under physiological conditions.

Administration of fasudil hydrochloride resulted in significantly more vessels with $A \beta$ in the hippocampi of both control and saporin-treated mice, while in the cortex, fewer vessels were found to contain $A \beta$ and this was observed in control mice only. Although the pattern of distribution was opposite between the two regions, we interpret both findings as representing increased IPAD at different rates of clearance. These findings are consistent with our CBF data and suggest that IPAD is significantly increased in the presence of vasodilation, which is in agreement with reports of impaired solute clearance from the brain during hypoperfusion [3, 37]. However, the similarity in the number of labeled cortical vessels between control + fasudil and saporin + fasudil mice suggests that other factors are also contributing to $A \beta$ clearance in denervated mice. Although blood pressure was not monitored in the current experiments, previous studies have shown that fasudil hydrochloride does not alter systolic blood pressure in normotensive rodents or humans $[44,51,57,59]$, suggesting that the observed effects were unlikely to be due to changes in peripheral blood pressure. In addition, no differences in vessel density or markers of microglia and astrocytes were observed between control and saporin mice in either brain region. Although our findings are consistent with reports of an association between decreased eNOS expression and increased CAA $[6,81]$, recent work has shown that NVC is mediated in part by arteriole caveolae independent of eNOS activation [17]. Further work is required to determine the factors that regulate $A \beta$ clearance when cholinergic signalling is attenuated.

Previous studies have reported a relationship between basal forebrain degeneration and $\mathrm{A} \beta$ pathology in the cortex [26] and basal forebrain atrophy has been suggested to predict cortical $A \beta$ burden [82]. Induced loss of cholinergic neurons in rodent models of AD has also been associated with increased $A \beta$ plaque deposition [48, 67], however most studies have not specifically investigated the effect on vascular $A \beta$. In the present study, administration of mu-saporin in TetO-APPSweInd mice resulted in a loss of cholinergic neurons that was only significant in the hippocampus. 
The reasons for the discrepancies between the degree of loss between the C57BL/6 and TetO-APPSweInd mice are not clear, but may relate to the dystrophic appearance of cholinergic fibers and decreased p75NTR:ChAT ratio observed in the TetO-APPSweInd mice. As binding of the p75NTR by $A \beta$ is known to induce apoptosis [95], it may be that pre-existing $A \beta$ pathology caused damage to cholinergic neurons and fibres that induced a downregulation in p75NTR expression and decreased receptor availability for musaporin binding.

Although unexpected, the difference in sensitivity to saporin treatment between the cortex and hippocampus provided an internal control to study the effect of cholinergic loss on $\mathrm{A} \beta$ pathology. We found that loss of cholinergic innervation in the hippocampus was associated with a significant increase in A $\beta 40$-positive vessels, consistent with the preferential deposition of A $\beta 40$ in the vasculature in AD [30, 80]. By contrast, CAA load was not affected in the cortex where cholinergic fibre density was not altered by saporin treatment. Parenchymal plaque load did not differ between control and saporin-treated mice in either region. These findings are consistent with previous studies showing significantly more endogenous CAA in the absence of changes in parenchymal changes or changes in APP processing in rabbits administered saporin [10, 70]. These findings are also similar to a study which found that age-related loss of perivascular cholinergic innervation in the cortex did not significantly correlate with increased cortical plaque load in the Tg2576 AD mouse model [46]. However, other studies have reported increased plaque load and elevated concentrations of soluble $A \beta$ following saporin-induced cholinergic loss in the APP/PS1 and Tg2576 mouse models [24, 48, 67]. Many factors may have contributed to these different observations, including the degree of cholinergic degeneration, age of the mice and amount of pre-existing $A \beta$ pathology before saporin treatment, as well as the ratio of $A \beta 40: A \beta 42$ and progression of pathology between the different mouse models. Despite these discrepancies, our results support a consensus that loss of cholinergic innervation contributes to increased $A \beta$ pathology.

In addition to the previously discussed limitations related to inducing NVC in the hippocampus of anesthetised animals and assessment of IPAD ex vivo, this study has several other weaknesses. The saporin model induces loss of basal forebrain cholinergic neurons in a retrograde manner [47], and over a more rapid timeframe than that observed in $\mathrm{AD}$, which may activate a strong acute inflammatory reaction and/or the development of compensatory mechanisms in the animal model that are not present in AD. In addition, as age is the major risk factor for both sporadic AD and CAA, additional experiments are needed to determine whether the effects of cholinergic denervation on $\mathrm{CBF}$ and IPAD in the cortex and hippocampus seen here in young adult mice are also observed in aged animals.

\section{Conclusions}

Despite these limitations, findings from this study support a role for loss of cholinergic innervation in the aetiology and/or progression of CAA and suggest that this may be related to eNOS-mediated vasodynamics that contribute to clearance of $A \beta$ from the brain via IPAD pathways. Therefore, combined targeting of eNOS and cholinergic signalling/activation may represent a new mechanism to improve the efficiency of $\mathrm{A} \beta$ removal and reduce its deposition as CAA.

\section{Supplementary Information}

The online version contains supplementary material available at https://doi. org/10.1186/s40478-020-01108-z.

Additional file $\mathbf{1}$ : Table 1 List of source of primary and secondary antibodies used for immunohistochemistry.

Additional file 2: Fig. 1 a-d Photomicrographs of diffuse parenchymal plaques identified by the anti-A 340 antibody (a) and senile plaques stained by the anti-A $\beta 42$ antibody (b) in TetO-APPSwelnd mice. No staining was observed after pre-absorption of the $A \beta 40$ antibody with $A \beta 40$ peptide (1:10 molar ratio, c). Sections incubated after pre-absorption of A 340 with anti-A $\beta 40+$ anti-A 342 (d) showed a similar pattern of staining to that of sections incubated with the anti-A 42 antibody alone. $\mathbf{e - h}$ No staining was observed in tissue sections from C57BI/6 mice incubated with fluorescently-conjugated secondary antibodies alone.

Additional file 3: Fig. $\mathbf{2}$ a-f Photomicrographs showing expression of ChAT (green), p75NTR (red) and their colocalization (yellow) in neurons in the medial septum ( $\mathbf{a}$ and $\mathbf{b}$ ) and fibers in the hippocampus ( $\mathbf{c}$ and $\mathbf{d}$ ) and cortex (e and $\mathbf{f}$ ) of C57BI/6 mice. Animals received an intracerebroventricular injection of either PBS (control, a, c and e) or mu-saporin (b, d and f). Saporin treatment significantly reduced expression of p75NTR, ChATpositive cell bodies and fibers in the medial septum (b), hippocampus (d) and cortex (f). Images of the hippocampus are composed of individual overlapping images stitched together using Fiji. Scale bars: $a, b, e, f=250$ $\mu \mathrm{m} ; \mathrm{c}$ and $\mathrm{d}=100 \mu \mathrm{m}$.

Additional file 4: Fig. 3 a and $\mathbf{b}$ Photomicrographs showing the distribution of $0.5 \mu \mathrm{L}$ human A $40-A F 555$ (red) at $400 \mu \mathrm{m}$ away from the injection site after 5 min post-injection (PI) into the hippocampus (a) and cortex (b) of control mice. The cerebrovascular basement membrane was labelled with anti-laminin (blue) and smooth muscle cells were identified with anti-a smooth muscle actin (green). c-e Photomicrographs showing the distribution of A $340-A F 488$ (green) in the cortex of C57BL/6 mice, at 400 $\mu \mathrm{m}$ away from the injection site. The volume and post-injection (PI) time is indicated for 3 combinations that were tested to determine the optimal parameters for quantification of A $\beta$-positive vessels. $\mathbf{f}-\mathbf{k}$ Photomicrographs and quantification of GFAP $(\mathbf{f}, \mathbf{g}, \mathbf{j})$ and Iba1 (h, i, $\mathbf{k})$ staining in the hippocampus (f, $\mathbf{h})$ and cortex (g, $\mathbf{i})$ of control (con, upper panels) and saporin-treated C57BI/6 mice (sap, lower panels). I-q Photomicrographs and quantification of GFAP $(\mathbf{I}, \mathbf{m}, \mathbf{p})$ and $\mathbf{I b a} 1(\mathbf{n}, \mathbf{o}, \mathbf{q})$ staining in the hippocampus (I, $\mathbf{n})$ and cortex ( $\mathbf{m}, \mathbf{o})$ of control (con, upper panels) and saporin-treated TetO-APPSwelnd mice (sap, lower panels). $n=3-5 /$ group. scale bars $=100 \mu \mathrm{m}$ 


\begin{abstract}
Abbreviations
7-Nl: 7-Nitroindazole; Aß: Beta amyloid; ACh: Acetylcholine; AChEl: Acetylcholinesterase inhibitor; AD: Alzheimer's disease; APP: Amyloid precursor protein; ASL: Arterial spin labelling; CAA: Cerebral amyloid angiopathy; CBF: Cerebral blood flow; CVBM: Cerebrovascular basement membranes; ChAT: Choline acetyltransferase; eNOS: Endothelial nitric oxide synthase; GAPDH: Glyceraldehyde 3-phosphate dehydrogenase; GFAP: Glial acidic fibrillary protein; Iba1: Ionized calcium binding adaptor molecule 1; ICV: Intracerebroventricular; IPAD: Intramural periarterial drainage; iNOS: Inducible nitric oxide synthase; ISF: Interstitial fluid; L-NAME: Nitro-L-arginine Methyl Ester Hydrochloride; MRI: Magnetic resonance imaging; MS: Medial septum; nNOS: Neuronal nitric oxide synthase; NVC: Neurovascular coupling; P75NTR: p75 neurotrophin receptor; ROCK: Rho- associated, coiled-coil containing protein kinase.
\end{abstract}

\section{Acknowledgements}

The authors wish to thank the staff at the BRU and BRF for their technical support.

\section{Authors' contributions}

SN planned and carried out experiments, data analysis and manuscript preparation and editing. JW carried out experiments and data analysis relating to MRI experiments. ROC contributed to experimental planning and manuscript editing. IAR contributed to experimental planning and data analysis. CAH contributed to experimental planning, data analysis and manuscript preparation and editing. All authors read and approved the final manuscript.

\section{Funding}

This work was supported by funds from Alzheimer's Research UK.

\section{Availability of data and materials}

The datasets used and/or analysed during the current study available from the corresponding author on reasonable request.

\section{Ethics approval and consent to participate}

All animal work was approved by the Animal Welfare and Ethics Research Boards (AWERB) at the OU, University of Southampton and UCL in accordance with Home Office regulations and project licences (PPL 70/8507 and PPL 30/3095) under the Animals (Scientific Procedures) Act 1986. Experiments were reported according to the ARRIVE guidelines.

\section{Consent for publication}

Not applicable.

\section{Competing interests}

The authors declare that they have no competing interests.

\section{Author details}

1 School of Life, Health and Chemical Sciences, Open University, Milton Keynes, UK. ${ }^{2}$ Centre for Advanced Bioimaging, UCL, London, UK. ${ }^{3}$ Clinical and Experimental Sciences, University of Southampton, Southampton, UK. ${ }^{4}$ Department of Biomedical and Life Sciences, Lancaster University, Lancaster, UK.

Received: 6 November 2020 Accepted: 15 December 2020 Published online: 07 January 2021

\section{References}

1. Aldea R, Weller RO, Wilcock DM, Carare RO, Richardson G (2019) Cerebrovascular smooth muscle cells as the drivers of intramural periarterial drainage of the brain. Front Aging Neurosci 11:1. https://doi.org/10.3389/ fnagi.2019.00001

2. Alsop DC, Casement M, de Bazelaire C, Fong T, Press DZ (2008) Hippocampal hyperperfusion in Alzheimer's disease. Neuroimage 42:12671274. https://doi.org/10.1016/j.neuroimage.2008.06.006

3. Arbel-Ornath M, Hudry E, Eikermann-Haerter K, Hou S, Gregory JL, Zhao L, Betensky RA, Frosch MP, Greenberg SM, Bacskai BJ (2013) Interstitial fluid drainage is impaired in ischemic stroke and Alzheimer's disease mouse models. Acta Neuropathol 126:353-364. https://doi.org/10.1007/s0040 $1-013-1145-2$
4. Arvanitakis Z, Leurgans SE, Wang Z, Wilson RS, Bennett DA, Schneider JA (2011) Cerebral amyloid angiopathy pathology and cognitive domains in older persons. Ann Neurol 69:320-327

5. Attems J, Quass M, Jellinger KA, Lintner F (2007) Topographical distribution of cerebral amyloid angiopathy and its effect on cognitive decline are influenced by Alzheimer disease pathology. J Neurol Sci 257:49-55

6. Austin SA, Katusic ZS (2020) Partial loss of endothelial nitric oxide leads to increased cerebrovascular beta amyloid. J Cereb Blood Flow Metab 40:392-403. https://doi.org/10.1177/0271678X18822474

7. Bakker EN, Bacskai BJ, Arbel-Ornath M, Aldea R, Bedussi B, Morris AW, Weller RO, Carare RO (2016) Lymphatic clearance of the brain: perivascular, paravascular and significance for neurodegenerative diseases. Cell Mol Neurobiol 36:181-194. https://doi.org/10.1007/s10571-015-0273-8

8. Ball KK, Cruz NF, Mrak RE, Dienel GA (2010) Trafficking of glucose, lactate, and amyloid-beta from the inferior colliculus through perivascular routes. J Cereb Blood Flow Metab 30:162-176. https://doi.org/10.1038/jcbfm .2009 .206

9. Bartus RT, Dean RL 3rd, Beer B, Lippa AS (1982) The cholinergic hypothesis of geriatric memory dysfunction. Science 217:408-414. https://doi. org/10.1126/science.7046051

10. Beach TG, Potter PE, Kuo YM, Emmerling MR, Durham RA, Webster SD, Walker DG, Sue LI, Scott S, Layne KJ et al (2000) Cholinergic deafferentation of the rabbit cortex: a new animal model of Abeta deposition. Neurosci Lett 283:9-12

11. Bedussi B, Almasian M, de Vos J, VanBavel E, Bakker EN (2018) Paravascular spaces at the brain surface: low resistance pathways for cerebrospinal fluid flow. J Cereb Blood Flow Metab 38:719-726. https://doi. org/10.1177/0271678X17737984

12. Brown DR, Hunter R, Wyper DJ, Patterson J, Kelly RC, Montaldi D, McCullouch J (1996) Longitudinal changes in cognitive function and regional cerebral function in Alzheimer's disease: a SPECT blood flow study. J Psychiatr Res 30:109-126. https://doi.org/10.1016/00223956(95)00032-1

13. Carare RO, Bernardes-Silva M, Newman TA, Page AM, Nicoll JAR, Perry VH, Weller RO (2008) Solutes, but not cells, drain from the brain parenchyma along basement membranes of capillaries and arteries. Significance for cerebral amyloid angiopathy and neuroimmunology. Neuropathol Appl Neurobiol 34:131-144

14. Carare RO, Hawkes CA, Jeffrey M, Kalaria RN, Weller RO (2013) Review: cerebral amyloid angiopathy, prion angiopathy, CADASIL and the spectrum of protein elimination failure angiopathies (PEFA) in neurodegenerative disease with a focus on therapy. Neuropathol Appl Neurobiol 39:593611. https://doi.org/10.1111/nan.12042

15. Cauli B, Tong XK, Rancillac A, Serluca N, Lambolez B, Rossier J, Hamel E (2004) Cortical GABA interneurons in neurovascular coupling: relays for subcortical vasoactive pathways. J Neurosci 24:8940-8949. https://doi. org/10.1523/JNEUROSCI.3065-04.2004

16. Caviedes A, Varas-Godoy M, Lafourcade C, Sandoval S, Bravo-Alegria J, Kaehne T, Massmann A, Figueroa JP, Nualart F, Wyneken U (2017) Endothelial nitric oxide synthase is present in dendritic spines of neurons in primary cultures. Front Cell Neurosci 11:180. https://doi.org/10.3389/ fncel.2017.00180

17. Chow BW, Nunez V, Kaplan L, Granger AJ, Bistrong K, Zucker HL, Kumar P, Sabatini BL, Gu C (2020) Caveolae in CNS arterioles mediate neurovascular coupling. Nature 579:106-110. https://doi.org/10.1038/s4158 6-020-2026-1

18. Dai W, Lopez OL, Carmichael OT, Becker JT, Kuller LH, Gach HM (2009) Mild cognitive impairment and alzheimer disease: patterns of altered cerebral blood flow at MR imaging. Radiology 250:856-866. https://doi. org/10.1148/radiol.2503080751

19. Di Marco LY, Farkas E, Martin C, Venneri A, Frangi AF (2015) Is vasomotion in cerebral arteries impaired in alzheimer's disease? J Alzheimers Dis 46:35-53. https://doi.org/10.3233/JAD-142976

20. Dorheim MA, Tracey WR, Pollock JS, Grammas P (1994) Nitric oxide synthase activity is elevated in brain microvessels in Alzheimer's disease. Biochem Biophys Res Commun 205:659-665. https://doi.org/10.1006/ bbrc.1994.2716

21. Dorr A, Sahota B, Chinta LV, Brown ME, Lai AY, Ma K, Hawkes CA, McLaurin J, Stefanovic B (2012) Amyloid-beta-dependent compromise of microvascular structure and function in a model of Alzheimer's disease. Brain 135:3039-3050. https://doi.org/10.1093/brain/aws243 
22. Francis PT, Palmer AM, Snape M, Wilcock GK (1999) The cholinergic hypothesis of Alzheimer's disease: a review of progress. J Neurol Neurosurg Psychiatry 66:137-147

23. Furchgott RF, Zawadzki JV (1980) The obligatory role of endothelial cells in the relaxation of arterial smooth muscle by acetylcholine. Nature 288:373-376. https://doi.org/10.1038/288373a0

24. Gil-Bea FJ, Gerenu G, Aisa B, Kirazov LP, Schliebs R, Ramirez MJ (2012) Cholinergic denervation exacerbates amyloid pathology and induces hippocampal atrophy in Tg2576 mice. Neurobiol Dis 48:439-446. https:// doi.org/10.1016/j.nbd.2012.06.020

25. Gratton JP, Fontana J, O'Connor DS, Garcia-Cardena G, McCabe TJ, Sessa WC (2000) Reconstitution of an endothelial nitric-oxide synthase (eNOS), hsp90, and caveolin-1 complex in vitro. Evidence that hsp90 facilitates calmodulin stimulated displacement of eNOS from caveolin-1. J Bio Chem 275:22268-22272. https://doi.org/10.1074/jbc.M001644200

26. Grothe MJ, Ewers M, Krause B, Heinsen H, Teipel SJ, Alzheimer's Disease Neuroimaging I (2014) Basal forebrain atrophy and cortical amyloid deposition in nondemented elderly subjects. Alzheimers Dement 10:S344-353. https://doi.org/10.1016/j.jalz.2013.09.011

27. Hawkes CA, Gatherer M, Sharp MM, Dorr A, Yuen HM, Kalaria R, Weller RO, Carare RO (2013) Regional differences in the morphological and functional effects of aging on cerebral basement membranes and perivascular drainage of amyloid-beta from the mouse brain. Aging Cell 12:224-236. https://doi.org/10.1111/acel.12045

28. Hawkes CA, Hartig W, Kacza J, Schliebs R, Weller RO, Nicoll JA, Carare RO (2011) Perivascular drainage of solutes is impaired in the ageing mouse brain and in the presence of cerebral amyloid angiopathy. Acta Neuropathol 121:431-443. https://doi.org/10.1007/s00401-011-0801-7

29. Hawkes CA, Sullivan PM, Hands S, Weller RO, Nicoll JA, Carare RO (2012) Disruption of arterial perivascular drainage of amyloid-beta from the brains of mice expressing the human APOE epsilon4 allele. PLoS ONE 7:e41636. https://doi.org/10.1371/journal.pone.0041636

30. Hernandez-Guillamon M, Delgado P, Penalba A, Rodriguez-Luna D, Molina CA, Rovira A, Alvarez-Sabin J, Boada M, Montaner J (2012) Plasma beta-amyloid levels in cerebral amyloid angiopathy-associated hemorrhagic stroke. Neurodegener Dis 10:320-323. https://doi. org/10.1159/000333811

31. Hladky SB, Barrand MA (2014) Mechanisms of fluid movement into, through and out of the brain: evaluation of the evidence. Fluids Barriers CNS 11:26. https://doi.org/10.1186/2045-8118-11-26

32. Hotta $H$ (2016) Neurogenic control of parenchymal arterioles in the cerebral cortex. Prog Brain Res 225:3-39. https://doi.org/10.1016/ bs.pbr.2016.03.001

33. Hotta H, Uchida S, Kagitani F, Maruyama N (2011) Control of cerebral cortical blood flow by stimulation of basal forebrain cholinergic areas in mice. J Physiol Sci 61:201-209. https://doi.org/10.1007/s1257 6-011-0139-x

34. Hu WT, Wang Z, Lee VM, Trojanowski JQ, Detre JA, Grossman M (2010) Distinct cerebral perfusion patterns in FTLD and AD. Neurology 75:881-888. https://doi.org/10.1212/WNL.0b013e3181f1 1e35

35. ladecola C, Zhang F (1996) Permissive and obligatory roles of NO in cerebrovascular responses to hypercapnia and acetylcholine. Am J Physiol 271:R990-1001. https://doi.org/10.1152/ajpregu.1996.271.4.R990

36. Iliff JJ, Wang M, Liao Y, Plogg BA, Peng W, Gundersen GA, Benveniste $H$, Vates GE, Deane R, Goldman SA et al (2012) A paravascular pathway facilitates CSF flow through the brain parenchyma and the clearance of interstitial solutes, including amyloid beta. Sci Transl Med 4:147ra111. https://doi.org/10.1126/scitranslmed.3003748

37. Iliff JJ, Wang M, Zeppenfeld DM, Venkataraman A, Plog BA, Liao Y, Deane R, Nedergaard M (2013) Cerebral arterial pulsation drives paravascular CSF-interstitial fluid exchange in the murine brain. J Neurosci 33:18190-18199

38. Iturria-Medina Y, Sotero RC, Toussaint PJ, Mateos-Perez JM, Evans AC, Alzheimer's Disease Neuroimaging I (2016) Early role of vascular dysregulation on late-onset Alzheimer's disease based on multifactorial datadriven analysis. Nat Commun 7:11934. https://doi.org/10.1038/ncomm s11934

39. Jack CR Jr, Knopman DS, Jagust WJ, Shaw LM, Aisen PS, Weiner MW, Petersen RC, Trojanowski JQ (2010) Hypothetical model of dynamic biomarkers of the Alzheimer's pathological cascade. Lancet Neurol 9:119-128. https://doi.org/10.1016/S1474-4422(09)70299-6
40. Jankowsky JL, Slunt HH, Gonzales V, Savonenko AV, Wen JC, Jenkins NA, Copeland NG, Younkin LH, Lester HA, Younkin SG et al (2005) Persistent amyloidosis following suppression of Abeta production in a transgenic model of Alzheimer disease. PLoS Med 2:e355. https://doi.org/10.1371/ journal.pmed.0020355

41. Jeffrey M, Gonzalez L (2007) Classical sheep transmissible spongiform encephalopathies: pathogenesis, pathological phenotypes and clinical disease. Neuropathol Appl Neurobiol 33:373-394. https://doi.org/10.111 1/j.1365-2990.2007.00868.x

42. Jellinger KA, Attems J (2006) Prevalence and impact of cerebrovascular pathology in Alzheimer's disease and parkinsonism. Acta Neurol Scand 114:38-46

43. Kalisch BE, Connop BP, Jhamandas K, Beninger RJ, Boegman RJ (1996) Differential action of 7-nitro indazole on rat brain nitric oxide synthase. Neurosci Lett 219:75-78. https://doi.org/10.1016/s0304-3940(96)13194-3

44. Kishi T, Hirooka Y, Masumoto A, Ito K, Kimura Y, Inokuchi K, Tagawa T, Shimokawa H, Takeshita A, Sunagawa K (2005) Rho-kinase inhibitor improves increased vascular resistance and impaired vasodilation of the forearm in patients with heart failure. Circulation 111:2741-2747. https:// doi.org/10.1161/CIRCULATIONAHA.104.510248

45. Kureishi Y, Kobayashi S, Amano M, Kimura K, Kanaide H, Nakano T, Kaibuchi K, Ito M (1997) Rho-associated kinase directly induces smooth muscle contraction through myosin light chain phosphorylation. J Biol Chem 272:12257-12260. https://doi.org/10.1074/jbc.272.19.12257

46. Kuznetsova E, Schliebs R (2013) beta-Amyloid, cholinergic transmission, and cerebrovascular system: a developmental study in a mouse model of Alzheimer's disease. Curr Pharm Des 19:6749-6765. https://doi. org/10.2174/13816128113199990711

47. Lapchak PA, Araujo DM, Carswell S, Hefti F (1993) Distribution of [125I] nerve growth factor in the rat brain following a single intraventricular injection: correlation with the topographical distribution of trkA messenger RNA-expressing cells. Neuroscience 54:445-460. https://doi. org/10.1016/0306-4522(93)90265-h

48. Laursen B, Mork A, Plath N, Kristiansen U, Bastlund JF (2013) Cholinergic degeneration is associated with increased plaque deposition and cognitive impairment in APPswe/PS1dE9 mice. Behav Brain Res 240:146-152. https://doi.org/10.1016/j.bbr.2012.11.012

49. Lecrux C, Hamel E (2016) Neuronal networks and mediators of cortical neurovascular coupling responses in normal and altered brain states. Philos Trans R Soc Lond B Biol Sci. https://doi.org/10.1098/rstb.2015.0350

50. Lecrux C, Sandoe CH, Neupane S, Kropf P, Toussay X, Tong XK, LacalleAurioles M, Shmuel A, Hamel E (2017) Impact of altered cholinergic tones on the neurovascular coupling response to whisker stimulation. J Neurosci 37:1518-1531. https://doi.org/10.1523/JNEUROSCI.1784-16.2016

51. Liu P, Zhang H, Tang Y, Sheng C, Liu J, Zeng Y (2014) Influence of Rho kinase inhibitor Fasudil on late endothelial progenitor cells in peripheral blood of COPD patients with pulmonary artery hypertension. Bosn J Basic Med Sci 14:40-44. https://doi.org/10.17305/bjbms.2014.2295

52. Lourenco CF, Santos RM, Barbosa RM, Cadenas E, Radi R, Laranjinha J (2014) Neurovascular coupling in hippocampus is mediated via diffusion by neuronal-derived nitric oxide. Free Radic Biol Med 73:421-429. https:// doi.org/10.1016/j.freeradbiomed.2014.05.021

53. LovickTA, Brown LA, Key BJ (1999) Neurovascular relationships in hippocampal slices: physiological and anatomical studies of mechanisms underlying flow-metabolism coupling in intraparenchymal microvessels. Neuroscience 92:47-60. https://doi.org/10.1016/s0306-4522(98)00737-4

54. Miners JS, Baig S, Palmer J, Palmer LE, Kehoe PG, Love S (2008) Abetadegrading enzymes in Alzheimer's disease. Brain Pathol 18:240-252

55. Montagne A, Zhao Z, Zlokovic BV (2017) Alzheimer's disease: a matter of blood-brain barrier dysfunction? J Exp Med 214:3151-3169. https://doi. org/10.1084/jem.20171406

56. Morris AW, Carare RO, Schreiber S, Hawkes CA (2014) The cerebrovascular basement membrane: role in the clearance of beta-amyloid and cerebral amyloid angiopathy. Front Aging Neurosci 6:251. https://doi.org/10.3389/ fnagi.2014.00251

57. Mukai Y, Shimokawa H, Matoba T, Kandabashi T, Satoh S, Hiroki J, Kaibuchi K, Takeshita A (2001) Involvement of Rho-kinase in hypertensive vascular disease: a novel therapeutic target in hypertension. FASEB J 15:10621064. https://doi.org/10.1096/fj.00-0735fje

58. Nag N, Baxter MG, Berger-Sweeney JE (2009) Efficacy of a murine-p75saporin immunotoxin for selective lesions of basal forebrain cholinergic 
neurons in mice. Neurosci Lett 452:247-251. https://doi.org/10.1016/j. neulet.2009.01.006

59. Nagata K, Kondoh Y, Satoh Y, Watahiki Y, Yokoyama E, Yuya H, Hirata Y, Shishido F, Hatazawa J, Kanno I et al (1993) Effects of fasudil hydrochloride on cerebral blood flow in patients with chronic cerebral infarction. Clin Neuropharmacol 16:501-510. https://doi.org/10.1097/00002826199312000-00003

60. Nicolakakis N, Hamel E (2011) Neurovascular function in Alzheimer's disease patients and experimental models. J Cereb Blood Flow Metab 31:1354-1370. https://doi.org/10.1038/jcbfm.2011.43

61. Nizari S, Carare RO, Romero IA, Hawkes CA (2019) 3D reconstruction of the neurovascular unit reveals differential loss of cholinergic innervation in the cortex and hippocampus of the adult mouse brain. Front Aging Neurosci 11:172. https://doi.org/10.3389/fnagi.2019.00172

62. Oomen CA, Farkas E, Roman V, van der Beek EM, Luiten PG, Meerlo P (2009) Resveratrol preserves cerebrovascular density and cognitive function in aging mice. Front Aging Neurosci 1:4. https://doi.org/10.3389/ neuro.24.004.2009

63. Paris D, Patel N, DelleDonne A, Quadros A, Smeed R, Mullan M (2004) Impaired angiogenesis in a transgenic mouse model of cerebral amyloidosis. Neurosci Lett 366:80-85

64. Partyka PP, Godsey GA, Galie JR, Kosciuk MC, Acharya NK, Nagele RG, Galie PA (2017) Mechanical stress regulates transport in a compliant 3D model of the blood-brain barrier. Biomaterials 115:30-39. https://doi. org/10.1016/j.biomaterials.2016.11.012

65. Paxinos G, Franklin K (2019) Paxinos and Franklin's the mouse brain in stereotaxic coordinates, 5th edn. Elsevier, Amsterdam, p 375

66. Perry EK, Morris CM, Court JA, Cheng A, Fairbairn AF, McKeith IG, Irving D, Brown A, Perry RH (1995) Alteration in nicotine binding sites in Parkinson's disease, Lewy body dementia and Alzheimer's disease: possible index of early neuropathology. Neuroscience 64:385-395. https://doi. org/10.1016/0306-4522(94)00410-7

67. Ramos-Rodriguez JJ, Pacheco-Herrero M, Thyssen D, Murillo-Carretero MI, Berrocoso E, Spires-Jones TL, Bacskai BJ, Garcia-Alloza M (2013) Rapid beta-amyloid deposition and cognitive impairment after cholinergic denervation in APP/PS1 mice. J Neuropathol Exp Neurol 72:272-285. https:// doi.org/10.1097/NEN.0b013e318288a8dd

68. Rikitake Y, Kim HH, Huang Z, Seto M, Yano K, Asano T, Moskowitz MA, Liao JK (2005) Inhibition of Rho kinase (ROCK) leads to increased cerebral blood flow and stroke protection. Stroke 36:2251-2257. https://doi. org/10.1161/01.STR.0000181077.84981.11

69. Rivera-Rivera LA, Turski P, Johnson KM, Hoffman C, Berman SE, Kilgas P Rowley HA, Carlsson CM, Johnson SC, Wieben O (2016) 4D flow MRI for intracranial hemodynamics assessment in Alzheimer's disease. J Cereb Blood Flow Metab 36:1718-1730. https://doi.org/10.1177/0271678X15 617171

70. Roher AE, Kuo YM, Potter PE, Emmerling MR, Durham RA, Walker DG, Sue LI, Honer WG, Beach TG (2000) Cortical cholinergic denervation elicits vascular A beta deposition. Ann NY Acad Sci 903:366-373

71. Rosengarten B, Paulsen S, Burr O, Kaps M (2009) Neurovascular coupling in Alzheimer patients: effect of acetylcholine-esterase inhibitors. Neurobiol Aging 30:1918-1923. https://doi.org/10.1016/j.neurobiola ging.2008.02.017

72. Sato A, Sato Y, Uchida S (2004) Activation of the intracerebral cholinergic nerve fibers originating in the basal forebrain increases regional cerebra blood flow in the rat's cortex and hippocampus. Neurosci Lett 361:90-93. https://doi.org/10.1016/.j.neulet.2004.01.004

73. Schmitz TW, Nathan Spreng R, Alzheimer's Disease Neuroimaging I (2016) Basal forebrain degeneration precedes and predicts the cortical spread of Alzheimer's pathology. Nat Commun 7:13249. https://doi.org/10.1038/ ncomms 13249

74. Sehba FA, Schwartz AY, Chereshnev I, Bederson JB (2000) Acute decrease in cerebral nitric oxide levels after subarachnoid hemorrhage. J Cereb Blood Flow Metab 20:604-611. https://doi.org/10.1097/00004647-20000 3000-00018

75. Shafer OT, Chen A, Kumar SM, Muller KJ, Sahley CL (1998) Injury-induced expression of endothelial nitric oxide synthase by glial and microglial cells in the leech central nervous system within minutes after injury. Proc Biol Sci 265:2171-2175. https://doi.org/10.1098/rspb.1998.0555
76. Shi J, Wei L (2013) Rho kinases in cardiovascular physiology and pathophysiology: the effect of fasudil. J Cardiovasc Pharmacol 62:341-354. https://doi.org/10.1097/FJC.0b013e3182a3718f

77. Shin HK, Jones PB, Garcia-Alloza M, Borrelli L, Greenberg SM, Bacskai BJ, Frosch MP, Hyman BT, Moskowitz MA, Ayata C (2007) Age-dependent cerebrovascular dysfunction in a transgenic mouse model of cerebral amyloid angiopathy. Brain 130:2310-2319

78. Shin HK, Salomone S, Potts EM, Lee SW, Millican E, Noma K, Huang PL, Boas DA, Liao JK, Moskowitz MA et al (2007) Rho-kinase inhibition acutely augments blood flow in focal cerebral ischemia via endothelial mechanisms. J Cereb Blood Flow Metab 27:998-1009. https://doi.org/10.1038/ sj.jcbfm. 9600406

79. Simic G, Babic M, Borovecki F, Hof PR (2014) Early failure of the defaultmode network and the pathogenesis of Alzheimer's disease. CNS Neurosci Ther 20:692-698. https://doi.org/10.1111/cns.12260

80. Suzuki N, Iwatsubo T, Odaka A, Ishibashi Y, Kitada C, Ihara Y (1994) High tissue content of soluble beta 1-40 is linked to cerebral amyloid angiopathy. Am J Pathol 145:452-460

81. Tan XL, Xue YQ, Ma T, Wang X, Li JJ, Lan L, Malik KU, McDonald MP, Dopico AM, Liao FF (2015) Partial eNOS deficiency causes spontaneous thrombotic cerebral infarction, amyloid angiopathy and cognitive impairment. Mol Neurodegener 10:24. https://doi.org/10.1186/s13024-015-0020-0

82. Teipel S, Heinsen H, Amaro E Jr, Grinberg LT, Krause B, Grothe M, Alzheimer's Disease Neuroimaging I (2014) Cholinergic basal forebrain atrophy predicts amyloid burden in Alzheimer's disease. Neurobiol Aging 35:482-491. https://doi.org/10.1016/j.neurobiolaging.2013.09.029

83. Thal DR, Griffin WS, de Vos RA, Ghebremedhin E (2008) Cerebral amyloid angiopathy and its relationship to Alzheimer's disease. Acta Neuropathol 115:599-609

84. Tian J, Shi J, Bailey K, Mann DM (2003) Negative association between amyloid plaques and cerebral amyloid angiopathy in Alzheimer's disease. Neurosci Lett 352:137-140

85. Tikka S, Mykkanen K, Ruchoux MM, Bergholm R, Junna M, Poyhonen M, Yki-Jarvinen H, Joutel A, Viitanen M, Baumann M et al (2009) Congruence between NOTCH3 mutations and GOM in 131 CADASIL patients. Brain 132:933-939. https://doi.org/10.1093/brain/awn364

86. Van Beek AH, Claassen JA (2011) The cerebrovascular role of the cholinergic neural system in Alzheimer's disease. Behav Brain Res 221:537-542. https://doi.org/10.1016/j.bbr.2009.12.047

87. van Opstal AM, van Rooden $\mathrm{S}$, van Harten T, Ghariq E, Labadie G, Fotiadis P, Gurol ME, Terwindt GM, Wermer MJH, van Buchem MA et al (2017) Cerebrovascular function in presymptomatic and symptomatic individuals with hereditary cerebral amyloid angiopathy: a case-control study. Lancet Neurol 16:115-122. https://doi.org/10.1016/S1474-4422(16)30346-5

88. van Veluw SJ, Hou SS, Calvo-Rodriguez M, Arbel-Ornath M, Snyder AC, Frosch MP, Greenberg SM, Bacskai BJ (2020) Vasomotion as a driving force for paravascular clearance in the awake mouse brain. Neuron 105(549561):e545. https://doi.org/10.1016/j.neuron.2019.10.033

89. Vaucher E, Linville D, Hamel E (1997) Cholinergic basal forebrain projections to nitric oxide synthase-containing neurons in the rat cerebral cortex. Neuroscience 79:827-836. https://doi.org/10.1016/s0306 $-4522(97) 00033-x$

90. Vinters HV (1987) Cerebral amyloid angiopathy. A critical review. Stroke 18:311-324

91. Wells JA, Holmes HE, O'Callaghan JM, Colgan N, Ismail O, Fisher EM, Siow B, Murray TK, Schwarz AJ, O'Neill MJ et al (2015) Increased cerebral vascular reactivity in the tau expressing $r T g 4510$ mouse: evidence against the role of tau pathology to impair vascular health in Alzheimer's disease. J Cereb Blood Flow Metab 35:359-362. https://doi.org/10.1038/jcbfm .2014 .224

92. Wiencken AE, Casagrande VA (1999) Endothelial nitric oxide synthetase (eNOS) in astrocytes: another source of nitric oxide in neocortex. Glia 26:280-290

93. Wilcock DM, Rojiani A, Rosenthal A, Subbarao S, Freeman MJ, Gordon MN, Morgan D (2004) Passive immunotherapy against Abeta in aged APPtransgenic mice reverses cognitive deficits and depletes parenchymal amyloid deposits in spite of increased vascular amyloid and microhemorrhage. J Neuroinflamm 1:24 
94. Williams RJ, Goodyear BG, Peca S, McCreary CR, Frayne R, Smith EE, Pike GB (2017) Identification of neurovascular changes associated with cerebral amyloid angiopathy from subject-specific hemodynamic response functions. J Cereb Blood Flow Metab 37:3433-3445. https://doi. org/10.1177/0271678X17691056

95. Yaar M, Zhai S, Pilch PF, Doyle SM, Eisenhauer PB, Fine RE, Gilchrest BA (1997) Binding of beta-amyloid to the p75 neurotrophin receptor induces apoptosis. A possible mechanism for Alzheimer's disease. J Clin Invest 100:2333-2340. https://doi.org/10.1172/JCl119772

96. Zecchin HG, Priviero FB, Souza CT, Zecchin KG, Prada PO, Carvalheira JB, Velloso LA, Antunes E, Saad MJ (2007) Defective insulin and acetylcholine induction of endothelial cell-nitric oxide synthase through insulin receptor substrate/Akt signaling pathway in aorta of obese rats. Diabetes 56:1014-1024. https://doi.org/10.2337/db05-1147

97. Zhang F, Xu S, ladecola C (1995) Role of nitric oxide and acetylcholine in neocortical hyperemia elicited by basal forebrain stimulation: evidence for an involvement of endothelial nitric oxide. Neuroscience 69:11951204. https://doi.org/10.1016/0306-4522(95)00302-y

\section{Publisher's Note}

Springer Nature remains neutral with regard to jurisdictional claims in published maps and institutional affiliations.
Ready to submit your research? Choose BMC and benefit from:

- fast, convenient online submission

- thorough peer review by experienced researchers in your field

- rapid publication on acceptance

- support for research data, including large and complex data types

- gold Open Access which fosters wider collaboration and increased citations

- maximum visibility for your research: over 100M website views per year

At BMC, research is always in progress.

Learn more biomedcentral.com/submissions 